\title{
Historical genomics reveals the evolutionary mechanisms behind multiple outbreaks of the host-specific coffee wilt pathogen Fusarium xylarioides
}

\author{
Lily D. Peck ${ }^{1,2^{*}} \mathbb{D}^{\mathrm{D}}$, Reuben W. Nowell ${ }^{2,3}$, Julie Flood ${ }^{4}$, Matthew J. Ryan ${ }^{4}$ and Timothy G. Barraclough²,3
}

\begin{abstract}
Background: Nearly 50\% of crop yields are lost to pests and disease, with plants and pathogens locked in an amplified co-evolutionary process of disease outbreaks. Coffee wilt disease, caused by Fusarium xylarioides, decimated coffee production in west and central Africa following its initial outbreak in the 1920s. After successful management, it later re-emerged and by the 2000s comprised two separate epidemics on arabica coffee in Ethiopia and robusta coffee in east and central Africa.

Results: Here, we use genome sequencing of six historical culture collection strains spanning 52 years to identify the evolutionary processes behind these repeated outbreaks. Phylogenomic reconstruction using 13,782 single copy orthologs shows that the robusta population arose from the initial outbreak, whilst the arabica population is a divergent sister clade to the other strains. A screen for putative effector genes involved in pathogenesis shows that the populations have diverged in gene content and sequence mainly by vertical processes within lineages. However, 15 putative effector genes show evidence of horizontal acquisition, with close homology to genes from F. oxysporum. Most occupy small regions of homology within wider scaffolds, whereas a cluster of four genes occupy a 20Kb scaffold with strong homology to a region on a mobile pathogenicity chromosome in $F$. oxysporum that houses known effector genes. Lacking a match to the whole mobile chromosome, we nonetheless found close associations with DNA transposons, especially the miniature impala type previously proposed to facilitate horizontal transfer of pathogenicity genes in F. oxysporum. These findings support a working hypothesis that the arabica and robusta populations partly acquired distinct effector genes via transposition-mediated horizontal transfer from F. oxysporum, which shares coffee as a host and lives on other plants intercropped with coffee.

Conclusion: Our results show how historical genomics can help reveal mechanisms that allow fungal pathogens to keep pace with our efforts to resist them. Our list of putative effector genes identifies possible future targets for fungal control. In turn, knowledge of horizontal transfer mechanisms and putative donor taxa might help to design future intercropping strategies that minimize the risk of transfer of effector genes between closely-related Fusarium taxa.

Keywords: Comparative genomics, Host adaptation, Fungi, Effector, Proteome, Fusarium oxysporum
\end{abstract}

\footnotetext{
*Correspondence: I.peck18@imperial.ac.uk

${ }^{1}$ Science and Solutions for a Changing Planet Doctoral Training Partnership,

Grantham Institute, Imperial College London, South Kensington, SW7 2AZ

London, UK

${ }^{2}$ Department of Life Sciences, Imperial College London, Silwood Park Campus,

Ascot, SL5 7PY Berkshire, UK

Full list of author information is available at the end of the article
}

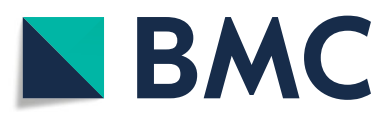

(c) The Author(s). 2021, corrected publication 20210pen Access This article is licensed under a Creative Commons Attribution 4.0 International License, which permits use, sharing, adaptation, distribution and reproduction in any medium or format, as long as you give appropriate credit to the original author(s) and the source, provide a link to the Creative Commons licence, and indicate if changes were made. The images or other third party material in this article are included in the article's Creative Commons licence, unless indicated otherwise in a credit line to the material. If material is not included in the article's Creative Commons licence and your intended use is not permitted by statutory regulation or exceeds the permitted use, you will need to obtain permission directly from the copyright holder. To view a copy of this licence, visit http://creativecommons.org/licenses/by/4.0/. The Creative Commons Public Domain Dedication waiver (http://creativecommons.org/publicdomain/zero/1.0/) applies to the data made available in this article, unless otherwise stated in a credit line to the data. 


\section{Background}

Fungal diseases have devastated major crop yields throughout history and continue to do so [1, 2]. Largescale planting of crops generates strong selection for new pathogens to emerge, which leads to further rounds of plant breeding to develop new resistant genotypes. This leads to "boom and bust cycles" that intensify the natural co-evolutionary dynamics of hosts and pathogens. A key goal for sustainable agriculture is therefore to predict disease outbreaks and design robust evolutionary solutions for long-term protection [3]. A first step towards this goal is to understand the genetic and evolutionary mechanisms by which pathogens overcome resistance and infect new host species. Plants have innate defence responses to detect and overcome pathogen attack [4]. In response, an emerging pathogen can evolve new mechanisms to suppress and overwhelm basal plant defences. These could arise by mutation (including gene duplication or loss), recombination and selection operating within a single population, or from hybridization and/or horizontal gene transfer between species to generate new pathogenicity variants $[5,6]$. Strong selection to evade plant immunity also leads to host-specificity, whereby pathogens evolve to target particular species or varieties [6]. For example, Fusarium oxysporum's well-studied host-specific formae speciales (f. sp.) cause disease on over 120 plant species, including Panama disease of bananas, F. oxysporum f. sp. cubense [7].

Comparative genomics is revealing the mechanisms that promote rapid evolution of effector proteins and host specificity in fungal pathogens. Effector genes are often found in highly mutable parts of the genome [8]. For example, in ascomycete fungi effectors often occupy ATrich compartments of the genome with high mutation rates or cluster with transposable elements (TEs), which increase variation via duplications, deletions, insertions and inversions [9-13]. In addition, many ascomycetes have mechanisms to facilitate horizontal transfer of effector genes between taxa either by "pathogenicity islands" in which pathogenicity genes and TEs cluster in chromsosomal segments depleted in GC [14] or by whole mobile chromosomes carrying suites of effectors [9]. For instance, the host-specific virulence protein ToxA was transferred among three wheat pathogens on an 14kb DNA fragment that is rich in transposons and still actively mobile in one of the species [15], whereas the ability of $F$. oxysporum $\mathrm{f}$. sp. lycopersici to infect tomatoes derives from a lineagespecific mobile chromosome, which can be transferred experimentally between strains. Pathogenicity can therefore evolve by mutation, recombination and selection operating within a single lineage, or from horizontal gene transfer between strains to generate new pathogenicity variants.
Although comparative genomics has uncovered mechanisms behind host specialisation in several fungal pathogens, exactly how these processes play out during disease cycles remains less clear. Studies have mostly compared contemporary lineages with different host specialisations, rather than tracking genetic changes over time. For example, understanding the roles of within-lineage evolution versus horizontal transfer in generating new effector gene combinations would benefit from comparing genomes before and after boom-bust cycles, as well as between differentially adapted host-specialists.

Here, we take advantage of six historic strains collected over 52 years to investigate successive outbreaks and the origin of host specialisation in Fusarium xylarioides Steyaert, a soil-borne fungal pathogen that causes coffee wilt disease (CWD). CWD first emerged as a devastating disease of Coffea excelsa and C. canephora crops in west and central Africa from the 1920s to 1960s [16, 17] (Fig. 1). Improved crop sanitation and breeding programmes successfully reduced its impact but CWD later re-emerged in the 1970s, spreading extensively throughout the 1990s and 2000s [20,21]. At around the same time that CWD re-emerged on robusta coffee, it was also reported in Ethiopia on "arabica" coffee (C. arabica) [22, $23]$ and $F$.xylarioides was confirmed as the causal agent $[24,25]$. By the 1990s, CWD was causing widespread destruction of arabica coffee in Ethiopia, and robusta coffee in the northeast Democratic Republic of Congo (DRC), Uganda and northern Tanzania [20]. It now comprises two host-specific and geographically separated populations, one on C. canephora robusta coffee in Uganda, Tanzania and DRC and the other on C. arabica in Ethiopia (Fig. 1). Both populations cause significant losses to the coffee cash crop, on Africa's two most valuable species [26, 27]. F. xylarioides therefore offers a unique study system with repeated epidemics and the emergence of two hostspecific populations [20, 28, 29]. Critically, historical living strains from the earlier pre-1970s outbreaks as well as the more recent, are optimally cryopreserved in a living state in culture collections.

Previous work described the pathology of the epidemics [20], clarified molecular taxonomy [29,30], showed reproductive isolation between the host-specialists [28], and reported the first genomes for the robusta population $[31,32]$. The genetic basis for successive outbreaks and host-specialisation remains unexplored, however. Wilting occurs when a pathogen proliferates in and blocks the host xylem, so restricting water transport [33, 34]. In order to colonize the xylem vascular system, effector proteins, including carbohydrate-active enzymes such as cellulases and pectinases, are required by the fungus to degrade and penetrate the root system [35, 36]. In F. oxysporum, effector proteins behind wilt induction (termed 


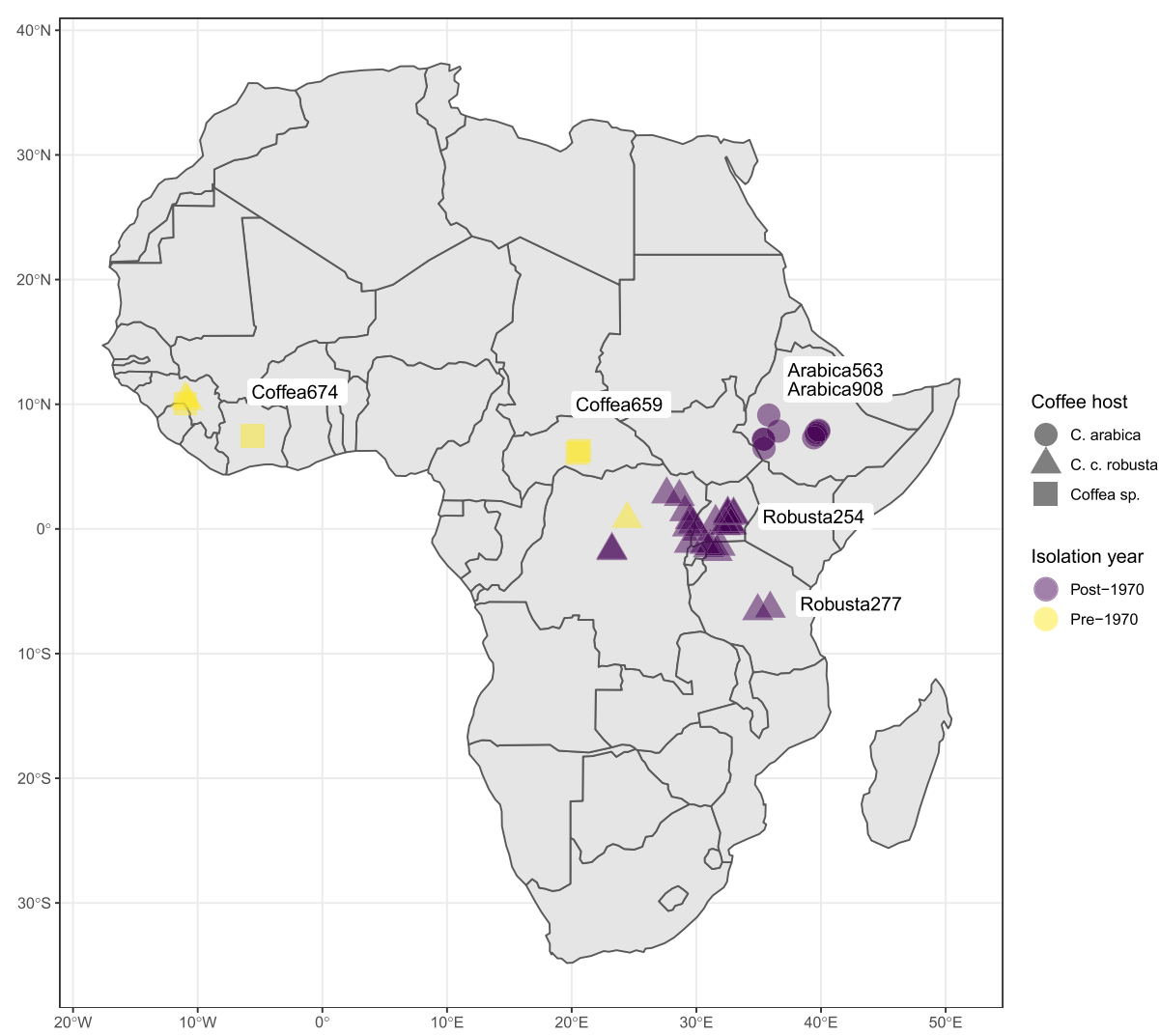

Fig. 1 The emergence and spread of F.xylarioides. A map of Africa detailing the year collected, country of origin and coffee plant host for the $62 F$. xylarioides strains in the CABI-IMI culture collection. These strains illustrate the spread west of CWD from the pre-1970s strains to the post-1970s strains, and the emergence of the host-specific arabica and robusta populations. The six strains sequenced in this study are labelled on the map as: Coffea674, from Cote D'Ivoire; Coffea659 from the Central African Republic; robusta254, from Uganda; robusta277, from Tanzania; arabica563 and arabica908, from Ethiopia. Map created in Rstudio 1.2.1335 using the Standard Features package [18] and drawn in ggplot2 [19]

SIX for Secreted In Xylem) are encoded by a single mobile, pathogenicity chromosome $[9,13]$. As a result, the same host-specific f. sp.'s can have polyphyletic origins, as the ability to infect a particular host is transferred horizontally [37-40]. Whether similar mechanisms apply for $F$. xylarioides and CWD, and how pathogenicity is restored between successive disease outbreaks, remains unknown. Intriguingly, coffee is intercropped with banana, and $F$. xylarioides and F. oxysporum have been co-isolated from roots of both plants in Uganda, and from coffee roots in Ethiopia [29, 41]. Indeed, $F$. oxysporum is able to infect coffee, where it induces a wilt but does not result in the trees' death [41]. These findings raise the possibility that F. xylarioides may have acquired certain pathogenicity genes from $F$. oxysporum, that has facilitated the recent outbreaks on coffee.

To address these questions, we sequenced and compared the genomes of six representative historical F. xylarioides strains from the CABI-IMI living culture collection: two strains derive from the 1950s and the pre-1970s outbreak in the Central African Republic and Cote D'Ivoire respectively: Coffea659 (IMI 127659/ DSMZ 62457) and Coffea674 (IMI 392674/ CBS 258.52). We call these Coffea strains because of their ability to infect multiple Coffea species including robusta, and their original hosts are unknown. Coffea674 is the ex-type and in common with most pre-1970s strains infects robusta and other Coffea species but not arabica [28]. Coffea659 is one of the few strains able to also infect arabica in trials and therefore is a true host generalist [20,42]. Our remaining four sequenced strains comprise these host-specific populations: two arabica strains (arabica563, IMI 389563 and arabica908, IMI 375908); and two robusta strains (robusta254, IMI 392254 and robusta277, IMI 392277), all collected five years apart between 1995-2005 (Fig. 1). Current evidence from molecular markers and crossing experiments supports the distinctiveness of the arabica and robusta populations $[28,30]$, but varies with respect to relationships between them and with the initial outbreak's Coffea strains. Differing studies show the 19902000s arabica and robusta populations as sister clades [43], or the 1990-2000s robusta population grouped with 
the Coffea strains from the pre-1970s outbreak [29], suggesting it arose from a subset of older strains from the initial outbreak whereas the arabica population is more divergent. Thus, we first tested the hypothesis that the robusta population derived from the pre-1970s outbreak with the arabica population emerging separately. We then compared putative effector genes between the strains. Specifically, we ask (i) whether the 1990-2000s robusta epidemic is genetically different to the earlier outbreak; (ii) whether the host-specialist robusta and arabica populations share similar sets of derived effector genes or whether their similar pathologies evolved independently; (iii) we test whether changes in pathogenicity and hostspecialism involved horizontal transfer of effector genes, or was restricted to within-lineage evolution in ancestral sets of effector genes using comparisons with potentially co-occurring and closely related Fusarium species, and (iv) explore the possible role of mobile chromosomes or transposable elements in any putative cases of horizontal transfer.

\section{Results}

General features of the genomes in comparison with other Fusarium species

We reconstructed genome assemblies from MiSeq Illumina reads using MEGAHIT [44] ranging in size from 58 $\mathrm{Mb}$ in the Coffea strains to $61 \mathrm{Mb}$ for the robusta strains and $63 \mathrm{Mb}$ for the arabica strains. The robusta genomes are larger than those previously sequenced ( $55 \mathrm{Mb})$, however they have a comparable size if scaffolds $<500 \mathrm{bp}$ are excluded (comprising $4 \mathrm{Mb}$ in total, Additional file 2 : Table S1). Rather than remove these, we included them in our analyses. We assume these genomes to be complete, based on synteny with the previously published $F$. xylarioides genomes (Additional file 2: Figure S1), high levels of contiguity (N50>40 kb) and $100 \%$ proteome completeness based on the presence of BUSCO genes (Table 1).

To evaluate our genomes further, we compared them to published genomes from a range of Fusarium taxa (Figs. 2, Additional file 2: Figures S2 and S3, Table S3). F. xylarioides has a larger genome than its closely related species from the Fusarium fujikuroi Complex (FFC) African clade (also known as the Gibberella fujikuroi complex GFC) [45], F. udum (56.4 Mb, [46]), which causes wilt on pigeon pea, and that of $F$. verticillioides (41.7 Mb, [9]), which is a non-wilt plant pathogen of maize. The genomes are similar in size, however, to the more distantly related F. oxysporum f. sp. lycopersici (Fol) strain $4287(60 \mathrm{Mb}$, [9]). Representative whole-genome alignments revealed the presence of the 11 syntenic core chromosomes shared by $F$. verticillioides, $F$. oxysporum and more distantlyrelated Fusarium taxa [9] in F. xylarioides (Additional file 2: Figures S2 and S3), and the additional genomic material compared with $F$. verticillioides (Additional file 2: Figure S3). To understand precisely which $F$. xylarioides scaffolds matched these syntenic chromosomes, we used reference-guided scaffolding to orient our contigs into chromosomes based on the de novo long-read sequencing $F$. verticillioides assembly [9]. This resulted in $85 \%$ of our contigs for each genome mapped to its syntenic chromosomes and un-aligned scaffolds (labelled "FV") of $F$. verticillioides, with the remaining $15 \%$ comprising shorter un-aligned scaffolds (Fig. 3). We then classified these unaligned scaffolds based on their presence and absence across other FFC species: those which are absent from $F$. verticillioides but which are present in $F$. udum and the historic Coffea659 strain are labelled "FXU" (F. xylarioides and-udum specific); those which are absent from $F$. verticillioides and F. udum and are shared with Coffea659 are labelled "FXS" (F.xylarioides-specific); and those which are not shared with Coffea659 and are unique to each $F$.

Table 1 Genome statistics for sequenced F. xylarioides strains

\begin{tabular}{|c|c|c|c|c|c|c|}
\hline Name & Coffea674 & Coffea659 & Robusta277 & Robusta254 & Arabica563 & Arabica908 \\
\hline Strain number & IMI392674 CBS258.52 & IMI127659i DSMZ62457 & IMI392277 & IMI392254 & IMI389563 & IMI375908i \\
\hline Year & 1951 & 1955 & 2003 & 1997 & 2002 & 1997 \\
\hline Origin & Cote d'Ivoire & Central African Republic & Tanzania & Uganda & Ethiopia & Ethiopia \\
\hline Host & Coffea & C. excelsa & C. c. robusta & C.c. robusta & C. arabica & C. arabica \\
\hline Genome Size Mb & 57.2 & 59.6 & 61.3 & 60.3 & 63.4 & 62.6 \\
\hline No. scaffolds & 3969 & 4843 & 5484 & 5369 & 7078 & 7264 \\
\hline N50 bp & 62845 & 55667 & 54978 & 56291 & 42705 & 41762 \\
\hline BUSCO \% & 100 & 100 & 100 & 100 & 100 & 100 \\
\hline GC \% & 43.3 & 43.5 & 43.1 & 43.1 & 42.1 & 42.2 \\
\hline Coding Genes & 14529 & 14732 & 14852 & 14588 & 14589 & 14654 \\
\hline Coverage \% & 36 & 35 & 34 & 34 & 33 & 33 \\
\hline
\end{tabular}

"Coverage" refers to the proportion of the genome covered by coding regions 


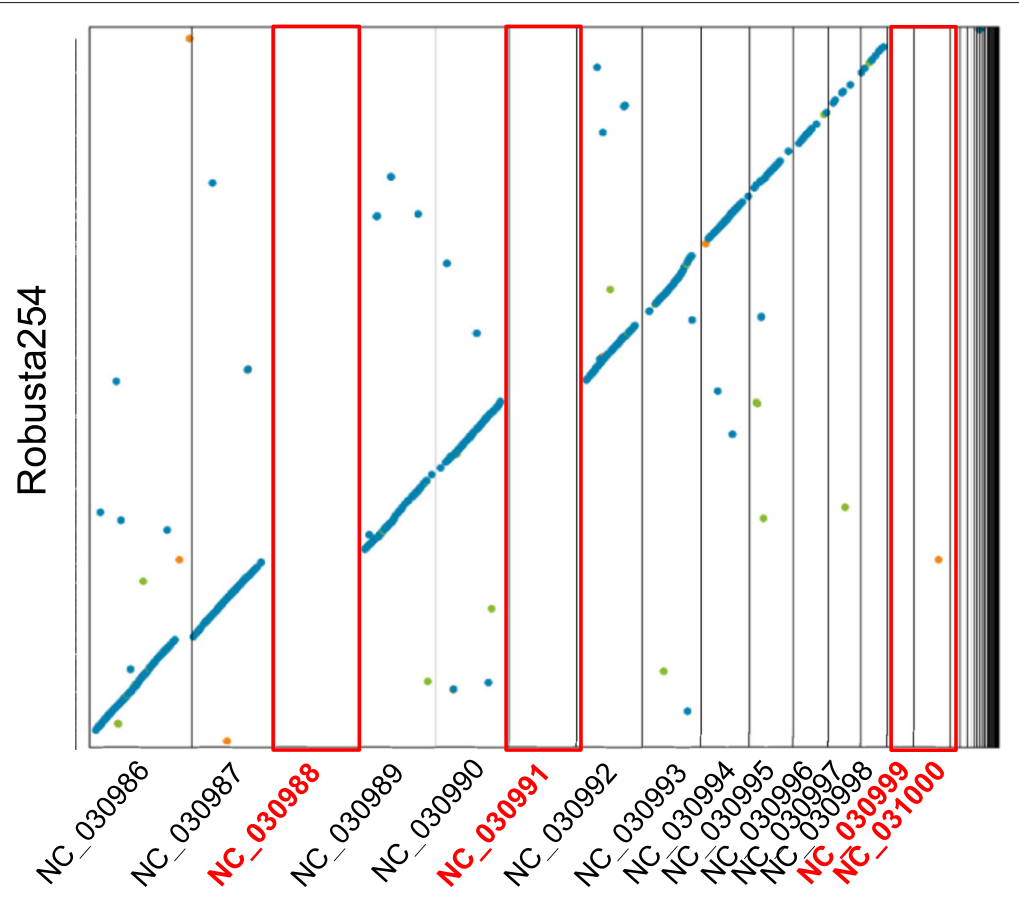

\section{F. oxysporum f. sp. lycopersici}

Fig. 2 Representative whole-genome alignments of F. xylarioides and F. oxysporum f. sp. lycopersici. Representative whole-genome alignments of $F$. xylarioides strain robusta277 against the 15 F. oxysporum f. sp. lycopersici chromosomes, including the 4 mobile chromosomes, annotated in red, and the 11 core chromosomes shared with sister Fusarium species [9]. Each dot represents chromosomal correspondence, with absences representing the absent Fol chromosomes. Alignments for each F. xylarioides genome are in Additional file 2: Figure S2. Genomes were aligned using Mummer 4.0.0 (http://mummer.sourceforge.net/) with outputs processed using Dotprep.py before visualizing using Dot in DNA Nexus (https://dnanexus. github.io/dot/). Blue indicates forward alignments, green indicates reverse alignments, orange indicates repetitive alignments

xylarioides strain are labelled "LS" (lineage-specific). The FXS scaffolds make up $<0.5 \%$ of the genomes, while LS scaffolds are $3.5 \%$ and FXU scaffolds are 12\% (Table 1). Genome size differences in the arabica and robusta strains are largely explained by the FXU and LS scaffolds $(11 \mathrm{Mb}$ and $9 \mathrm{Mb}$ respectively) (Additional file 2: Table S2).

F. xylarioides and F. udum are the only known members of the FFC to infect their target hosts with a wilt disease $[47,48]$. To test whether $F$. xylarioides might have evolved new wilt capabilities by acquiring a pathogenic chromosome from $F o l$, we mapped the F.xylarioides genomes to the Fol genome assembly. Chromosomes 3, 6, 14 and 15 in the Fol genome are supernumerary, or mobile, as well as parts of chromosomes 1 and 2 [9]. Chromosome 14 is also pathogenic, housing all known $\mathrm{Fol}$ wilt effector genes. We found no large-scale matches to any of the fully mobile chromosomes in F. xylarioides (Fig. 2 and Additional file 2: Figure S2), ruling out the recent transfer of the whole Fol mobile pathogenic chromosome. However, there was a significant excess of smaller matches between the LS and FXU scaffolds and the Fol mobile chromosomes (Additional file 2: Figure S4, Pearson's chi-sq test: $\mathrm{p}<0.001$ ). Potentially, this is consistent with smaller pieces having been transferred: $7 \%$ of the FXU scaffolds and $20 \%$ of the LS scaffolds matched to the four fully mobile Fol chromosomes (3, 6, 14 and 15), whereas $<2 \%$ matched to non-mobile chromosomes. With short-read sequencing we cannot infer the chromosomal assembly of the LS and FXU scaffolds nor rule out that $F$.xylarioides has novel mobile chromosomes not closely related to those in $F$. oxysporum. However, the pattern of strong hits to parts of the $\mathrm{Fol}$ mobile pathogenic chromosome but lack of hits to the majority of it does raise the possibility of transfer of smaller genome regions that we explore further below using alternative evidence.

Annotation of genes and transposable elements (TEs) in the MEGAHIT assemblies reveal the whole genomes, along with $F$. udum, contain on average 14,650 predicted protein-coding genes, covering $34 \%$ of the genomes and $5 \mathrm{Mb}$ of repeats, covering 9\% (Table 1 and Additional file 2: Table S1). Within our reference-guided assemblies, we found the FXU and LS scaffolds differ considerably in overall genomic content. The 11 core chromosomes along with the FV scaffolds are gene-rich and repeat-poor, whereas the FXU and LS scaffolds are gene-poor and repeat-rich (Fig. 3). The distribution of genes attributed 


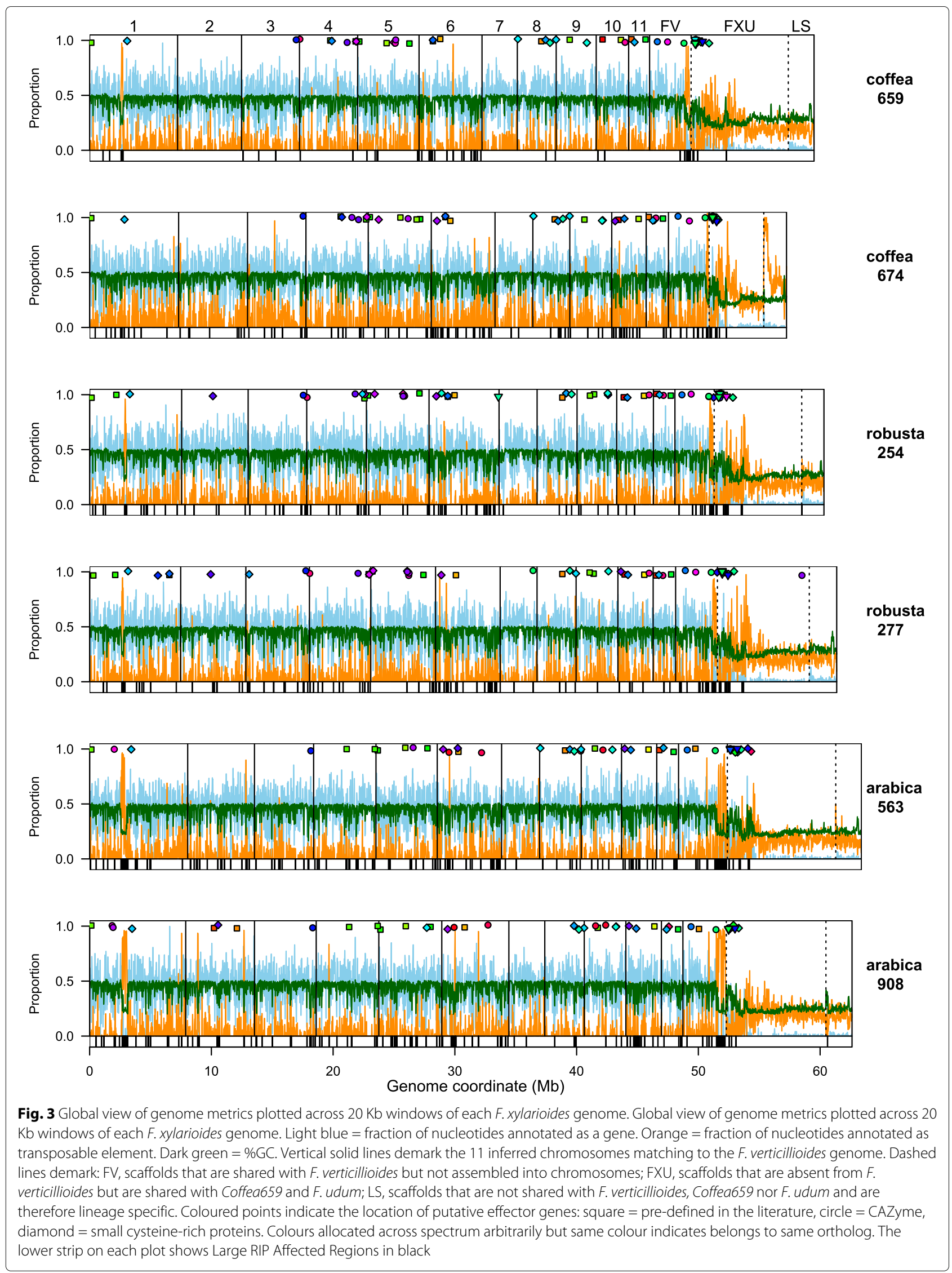


to particular functional classes was highly concordant among the six F. xylarioides strains, and within each core chromosome except chromosome 11, which is enriched for putative functions related to stress response and protection from reactive oxygen species (Additional file 2: Figure S5). Interestingly, genes on FXU and LS scaffolds are also enriched for the putative function 'phage major capsid proteins' (Additional file 2: Figure S5b), which could be involved with movements of mobile elements. In terms of TEs, we found consistent content across both the MEGAHIT and our reference-guided genome assemblies of $5 \mathrm{Mb}$ of interspersed repeats made up of simple repeats, retroelements and DNA transposons. We found slightly less $(4 \mathrm{Mb})$ if we analysed the raw reads which shows that our methods find more TEs than an assemblyfree method (Additional file 2: Table S1). In contrast, the FXU and LS scaffolds are enriched for transposable elements, which overall comprise $24 \%$ of DNA in these scaffold groups, compared to $5 \%$ in the 11 core chromosomes. Within this, retrotransposons have contributed to genome expansion in F.xylarioides, as is commonly observed in other fungi [13], making up 16\% of DNA in these scaffold groups, compared to $3 \%$ in the 11 core chromosomes. The LS scaffolds are further enriched for DNA transposons, with $150 \%$ more than is found in the FXU scaffolds and $360 \%$ more than in the core chromosomes. The proportion of the whole genome made up of transposable elements also varies among species. Some of these differences could reflect bias due to different assembly methods. For instance, $F$. oxysporum has a high repetitive sequence and TE content: we calculated 6.2 Mb TEs from the Fol long-read assembly (Additional file 2: Table S1), which is considerably more than the number we calculated from the Fol raw reads $(1.2 \mathrm{Mb}$, Additional file 2: Table S1). It is possible that future longread sequencing would also reveal more TEs in our $F$. xylarioides strains. Despite this potential bias, however, $F$. xylarioides, has nearly $1000 \%$ more TEs than recovered from the whole chromosome assembly of $F$. verticillioides (Additional file 2: Table S1).

The F. xylarioides genomes display another common structural feature of plant pathogenic ascomycetes, namely the presence of AT-rich genome blocks. Specifically, the Repeat-Induced Point-like (RIP) mutations pathway is a genome defence mechanism against the invasion of mobile transposons that has been linked to enhanced mutagenesis of effector genes in some plant pathogens [8]. It is unique to ascomycete fungi and mutates cytosine bases to thymine in repeated genome sequences [49]. This leads to AT-rich sequences that are typically low in coding gene content, and can segment the genome into equilibrated compartments (as in Leptosphaeria maculans, [11]). Across both MEGAHIT and reference-guided assemblies, we find significant evidence for AT-rich blocks (averaging 21.5\% GC), which are spread throughout the core chromosomes and FV scaffolds, and the FXU and LS scaffolds (Fig. 3). On average, these blocks are significantly poor in genes but rich in repeats, in common with patterns in other fungi. We find that RIP regions make up $>33.5 \%$ to $>40 \%$ of each genome, with $>7.7 \%$ to $>8.5 \%$ of the genomes in so-called Large RIP Affected Regions (LRARs, (Fig. 3). Having described the broad features of our genomes we now address our questions concerning the multiple outbreaks.

\section{The arabica population arose independently from the robusta and Coffea strains}

Our genome data supports the previous hypothesis that the arabica and robusta populations emerged independently within F. xylarioides [29]. Gene annotations from the F.xylarioides and F. udum strains together with ten other published Fusarium and Verticillium wilt genomes were used to identify 18569 orthologous gene sets, encompassing 25,0056 genes or $95.6 \%$ of all annotated genes. The species tree based on the concordance of 13,782 gene trees of all ortholog groups supports the established order of the FFC [45] as well as the monophyly of $F$.xylarioides, with over $87 \%$ of genes supporting monophyly of the clade (Fig. 4). No alternate topology was consistently found for the remaining gene trees (the next most common was supported by just $1.1 \%$ of genes), confirming that $F$. xylarioides did not originate by hybridisation or major influx of genes from other taxa. Within the $F$. xylarioides clade, the arabica strains are recovered as a sister clade to the robusta and Coffe $a$ strains with high concordance of gene trees, consistent with them constituting genetically isolated taxa. While the two robusta strains are also monophyletic with high concordance, there is little concordance for their branching order with respect to Coffea strains: loci vary in whether robusta strains are closer to Coffea659 or to Coffea674. Whilst analysis of more strains is needed to confirm this conclusion, it fits the hypothesis that the robusta population emerged from within a wider recombining population of the more genetically diverse Coffea isolates, whereas the arabica population is a more divergent lineage within the $F$.xylarioides clade.

This conclusion is further supported by patterns of presence and absence of genes. Over $96 \%$ of single gene copies were shared between the two arabica and between the two robusta strains respectively, while there is less similarity between other $F$. xylarioides comparisons: Coffea-robusta, 93\%; Coffea-Coffea, 92\%; Coffea-arabica, 92\%; arabicarobusta, 91\%; and F. xylarioides-F. udum: 84\% (Fig. 5a). The robusta strains share a significantly higher proportion of orthologous gene sets with Coffea659 (SuperExactTest, $\mathrm{p}<0.001$ ), and they generally display more concordance with the Coffea strains, while the arabica strains 


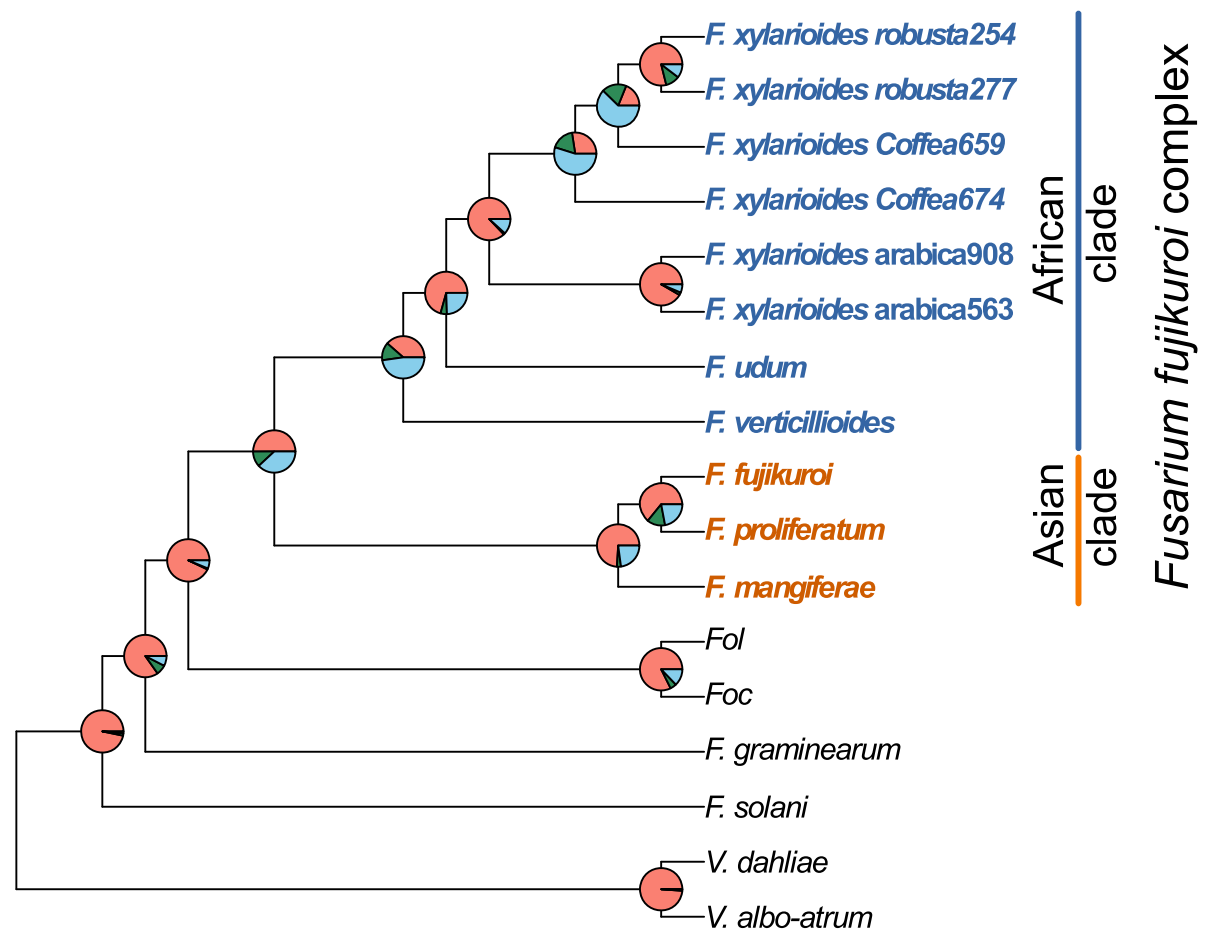

Fig. 4 Phylogenetic relationships between Fusarium species. Phylogenetic relationships between Fusarium species reconstructed from 13782 orthogroups support monophyly of the F.xylarioides clade, with little consistent support for alternate topologies. Strain accession numbers are in Additional file 2: Table S3. The brackets denote the FFC, with the Asian (blue) and African (red) clades. Pie chart colours: pink = proportion of genes (orthogroups) recovering the depicted node; dark green = the proportion of genes recovering the second most common topology; light blue = the proportion of genes recovering all other topologies

have the most unique orthogroups. The arabica strains share slightly more genes with the ex-type strain Coffea674 than with Coffea659 despite the latter being the only known strain able to infect both arabica and robusta coffee $[29,50]$.

\section{A set of putative effector proteins for F. xylarioides}

The proteome of plant pathogens includes pathogenicity factors and effector proteins, which are secreted to enable pathogen entry, survival and effective colonisation in their host. Thus fungal effector proteins are typically under positive selection and do not show conserved protein sequences $[8,51]$. Therefore, we adopted a multi-dimensional approach to look for putative effector proteins, namely those which enable the pathogen to become established in its host and trigger the onset of symptoms and a host defence response. We describe three classes: (i) those known from other fungal pathogens, (ii) small and cysteine-rich proteins, (iii) carbohydrateactive enzymes, and (iv) genes with class II TEs in their promoter regions, specifically including the presence of miniature impala (mimp) transposons which are associated with $F$. oxypsorum effector genes [13]. We also annotated the following characteristics: presence of positive selection indicating genes which are under accelerated evolution; presence of a signal peptide for secretion, because it is assumed that effector proteins need to be secreted during host colonisation; genes which are present in an AT-rich genome block as an indicator of potential transposon invasion; the predicted function based on the Pfam domain; and genes which are absent from sister FFC species and share F. oxysporum as the closest match with a percent identity above $90 \%$. Altogether, this process identified 64 putative effector genes, which were distributed across scaffolds and the referenceguided scaffold assemblies, and were mostly recovered in the same location in each strain (Fig. 3). Because effector genes have not been investigated previously in F. xylarioides, we first describe general findings for each category of effector genes, before focusing on the differences between the different host-specific populations.

\section{Putative effector genes known from other species}

We found BLAST matches in F.xylarioides to 19 known effector proteins previously characterised in $F$. oxysporum and other wilt-inducing pathogenic fungi, including some that are only recently discovered and unnamed (Additional file 2: Table S4, Fig. 6). The effector genes fow1, fmk1, snf1, pelD, chlo-vacu, rho1 (here with two copies rho1.1 and rho1.2), pep1, pelA, orx1, FOXG_14254 


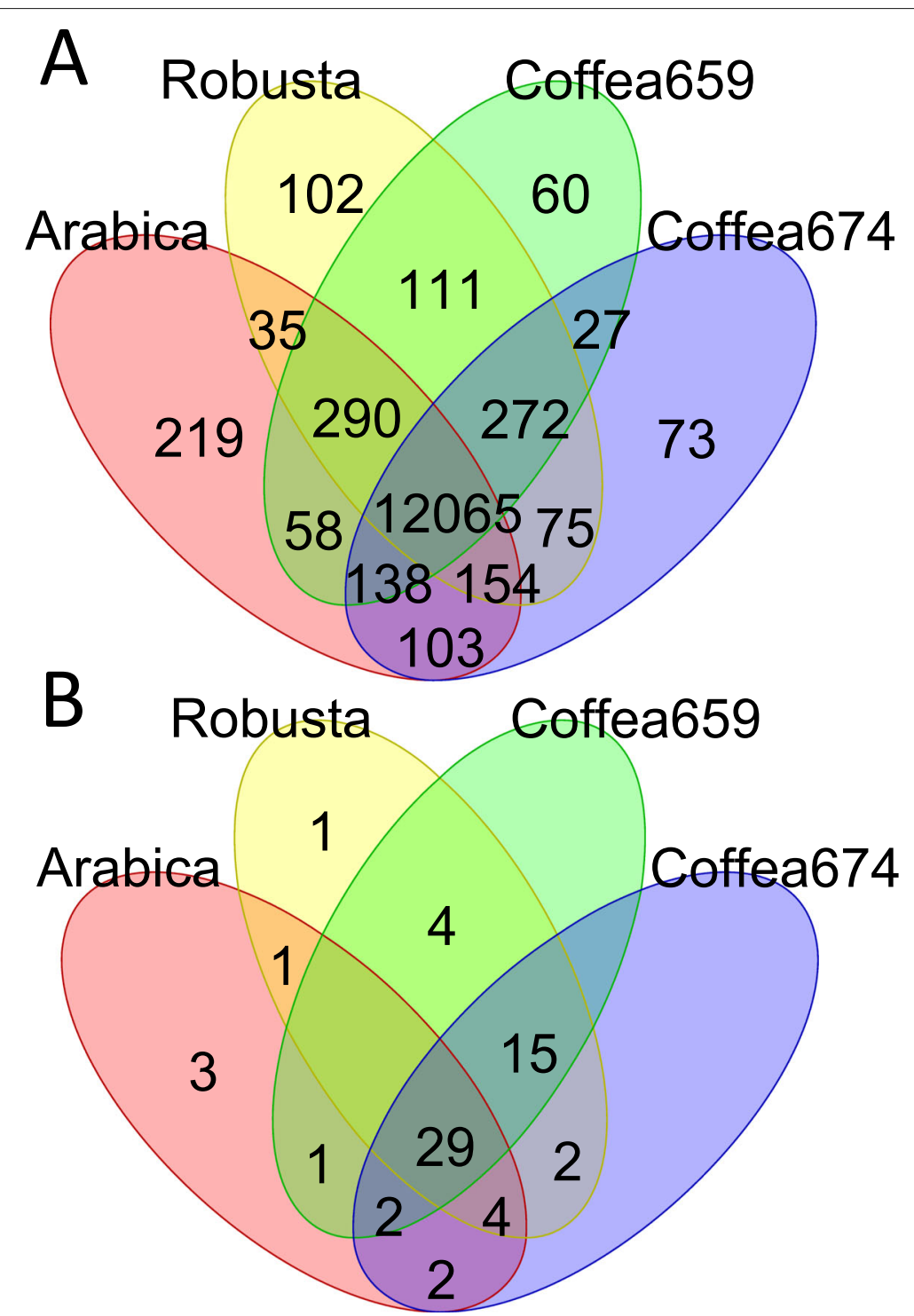

Fig. 5 Gene sharing across the F. xylarioides strains. a) Orthogroups shared between F. xylarioides arabica, robusta and the two Coffea strains. Drawn using 13782 orthogroups (excluding 449 F.xylarioides robusta orthogroups and 175 F.xylarioides arabica orthogroups that differed in presence/absence between the two strains of each population. The two Coffea strains are more divergent (with 1123 orthogroups that differ in presence/absence between the two strains) and so are drawn separately. The two arabica strains (563 and 908) share 13062 genes and the two robusta strains (254 and 277) share 13104 genes in total. b) Putative effectors shared between F. xylarioides arabica, robusta and the two Coffea strains. Drawn using 64 putative effector proteins that differed in presence/ absence across the host-specific populations

and catalase-peroxidase as well as the transcription factor Sge1 were found in all six F. xylarioides strains, with nep1, glucosyltransferase, pda1, six7, six10 and cytoskeletal found across the host-specific pairs. The majority of the well-characterised SIX effectors from Fol chromosome 14 are absent in both $F$. udum and all $F$.xylarioides strains, with the exceptions of the recently described Six 10 and Six7 proteins [13] which are present in arabica and Coffea strains, and the transcription factor Sge1, which is required for the expression of SIX genes [7], is found in all strains.

\section{Small and cysteine-rich secreted proteins}

Many fungal effector proteins are small $(<400$ amino acids), cysteine-rich ( $>4$ cysteine residues) and secreted $[8,52]$. Searching our annotated proteomes for these properties discovered over 2,500 small, cysteine-rich proteins in each strain, of which over 500 also have a signal peptide and a signal peptide cleavage site. Focusing on single copy genes for ease of comparison left 132 putative effectors in 21 orthologous groups shared across Fusarium and Verticillium (Fig. 6). Patterns of presence and absence were variable among these genes: ten were 


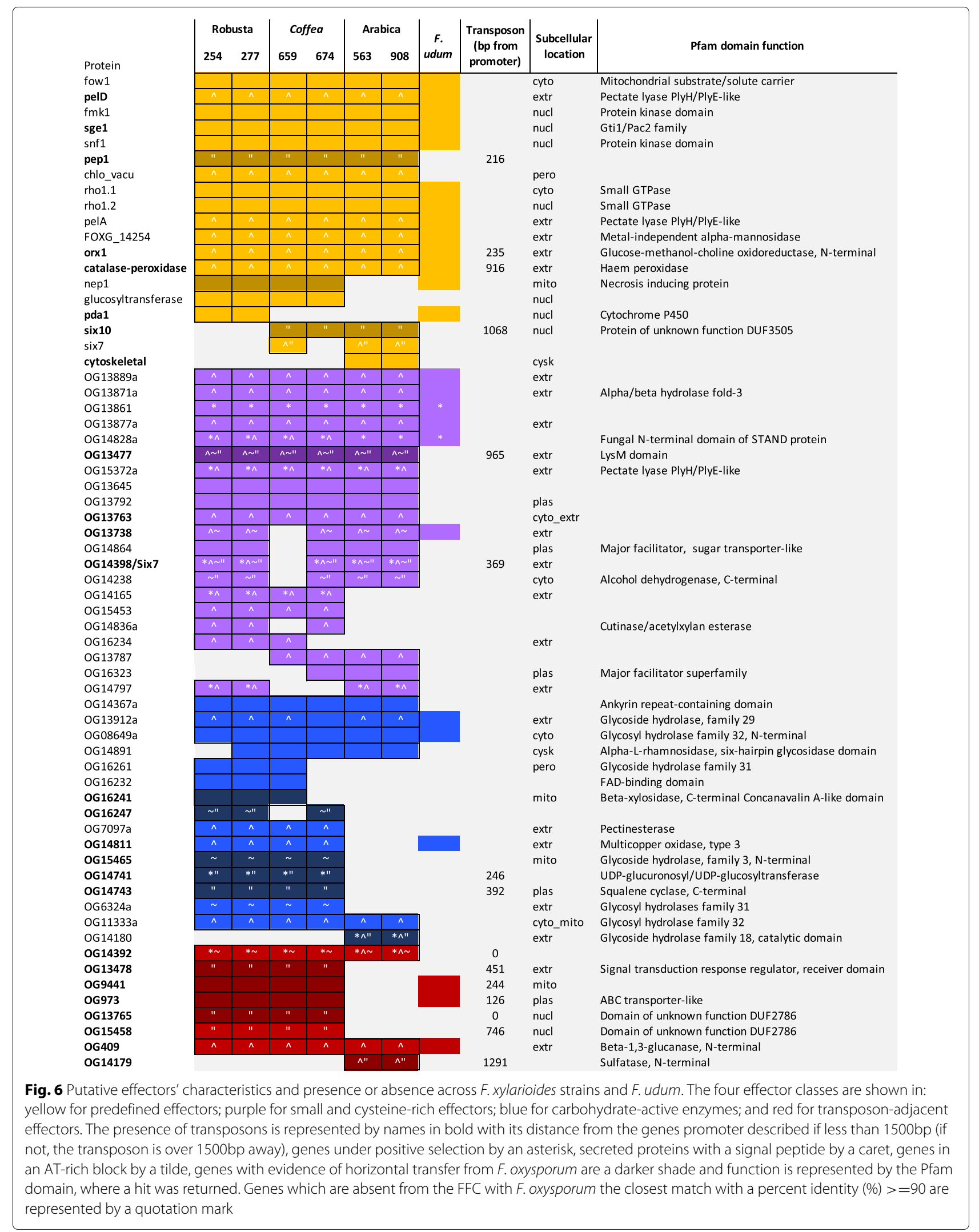


recovered in all F. xylarioides strains. Many of these genes had no recognisable Pfam domain function identified by InterPro (Fig. 6). This is expected because there are large numbers of unknown small and cysteine-rich proteins secreted in the apoplast (as part of the water-transport pathway) which are typically species- or strain-specific with no known function [8]. However, the orthogroup OG13477, found in all F.xylarioides strains, matches the LysM-containing chitin oligosaccharide protein, which in Cladosporum fulvum is required for scavenging of chitin oligosaccharides as a conserved fungal defence to enable undetected invasion [53]. Orthogroup OG14398 displayed a match, albeit with a relatively low BLAST score, to a number of six 7 F. oxysporum genes and protein sequences (e.g. MG647014.1) (notably not the Fol 4287 sequenced genome used for this comparative analysis), which might indicate that it is a divergent type of Six7 effector compared to previously described copies. Other functional annotations reveal a recurring theme of pectin degradation (expanded in next section): OG13871 is a hydrolase; OG15372 is a pectin lyase and OG14836 a carbohydrate esterase 5 with a carbohydrate binding module (CBM1); while OG14864 and OG16323 are major facilitator proteins involved in the transport of solutes, which could influence wilting.

\section{Carbohydrate-active enzymes}

Carbohydrates such as cellulose and pectin in plant cell walls provide the main source of carbon for fungal pathogens [54] and so carbohydrate-active enzymes (CAZymes) are thought to be important in the infection pathway. We therefore searched for CAZymes restricted to some or all of the wilt-inducing species of Fusarium and Verticillium and classified their carbohydrate-binding modules (CBMs) to characterise specificity for particular polymers. Our search found 56 genes of interest belonging to 16 orthogroups (Fig. 6). As a whole, Fusarium is broadly enriched for lytic enzymes involved in carbohydrate metabolism along with other ascomycete fungi [55, 56] (Additional file 2: Table S5), while the vascular wilt inducers show enrichment in certain gene families (Additional file 2: Figure S10), also reported by [10]). Fungal growth on pectin requires either the combined activities of pectin esterases and polygalacturonases or the sole activity of pectate lyases [34, 57], and all three enzymes are known from other wilt-inducing fungi [5860]. Interestingly, each share orthologous groups across the wilt-inducing strains analysed in this study (Additional file 2: Figure S10). A polygalacturonase enzyme (glycoside hydrolase (GH) family 28 ) from $F$. oxysporum, has expanded by one copy number in all $F$.xylarioides strains. Pectate lyase carbohydrate-binding modules CBM66 and CBM38, which bind a fructose-hydrolysing GH32, and chitin-cleaving CBM18 and CBM50 are also found across all six F. xylarioides strains (as well as $F$. udum and Fol). In contrast pectin esterases have expanded differentially among different $F$. xylarioides strains (see next section).

\section{Putative effectors with class II TEs in their promoter regions}

Effector genes in F. oxysporum are associated with Class II TEs [13]. There is a certain type of class II TE known as a mimp for miniature impala (part of the miniature inverted-repeat transposable element (MITE) family) which was first described in F. oxysporum [61]. In Fol, [13] reported that mimps (along with several other newly described types of class II TEs) are mostly found on the accessory chromosomes and within the promoter regions of the SIX effector genes [13]. Furthermore, mimps have recently been found in a few FFC species [62] and phylogenetic evidence supported repeated transfers between F. oxysporum and FFC species. Consequently, we looked for a final class of putative effectors that met four criteria: they were present in both strains for each host-specific population; they contained mimps or the newly described transposon families from [13] in their promoter regions (defined as $1500 \mathrm{bp}$ upstream from the start codon); they were on FXU or LS scaffolds; and they matched regions of Fol's mobile chromosomes. This resulted in eight additional putative effectors to supplement those identified by our three original criteria, with three containing mimps, two containing hop3, two containing yaret 2 and one with yaret1 DNA transposons (Fig. 6). Additionally, 15 putative effectors from the predefined, small and cysteine-rich and CAZyme classes also shared a scaffold with a transposon, with four genes across the robusta and Coffea strains (catalase peroxidase, og14741, og14743, og14398) and six 10 across the arabicas with mimps in their promoter regions. The potential role of transposition on effector gene evolution is investigated further in section 3.6 - for now we treat them simply as another class of putative effector genes.

\section{Host-specific populations differ in their complement of putative effectors}

Effector gene presence and absence recapitulated findings from the whole genome analyses: both strains from the same host-specific population nearly always share the same effector gene complement, and the robusta population and Coffea strains share greater overlap in effector gene complement (SuperExactTest, $\mathrm{p}=0.001$ ) than either do with the arabica population (Fig. 5b). Based on this significant association, we looked for changes that might have led to specialisation on robusta coffee and increased virulence, and found just 1 effector unique to the robusta strains, $p d a 1$. This gene encodes the enzyme pisatin demethylase, which has been shown to detoxify the plant defensive compound (phytoalexin) pisatin by $F$. oxysporum f. sp. pisi in peas, and with different alleles 
present across different $F$. oxysporum host-specific f. sp.'s $[39,63,64]$. Interestingly, in sugarbeet one pda1- $a$ allele (accession AY487143.1) was only found in pathogenic strains [63], although the gene copy found in this study is $97 \%$ similar to a pda 1 from $F$. oxysporum $f$. sp. phaseoli and is only $62 \%$ similar to the pathogenic sugarbeet allele. The enzyme could have a direct role against related phytoalexin compounds in coffee or enable growth of robusta strains on alternative hosts. However, given that both Coffea674 and Coffea659 lack pda1 it is unlikely this gene is essential for robusta infection. Indeed, with the exception of pda1, the robusta population is more unique in the genes that it lacks than in the genes it has gained when compared with the Coffea strains. Because plant immune systems are triggered by detection of secreted effector proteins, the loss of genes might also be important for pathogenicity on different hosts, should plants evolve to recognise certain effectors. Four orthogroups that are present in one or both Coffea strains are missing from the robusta strains: six7, six10, OG13787 and OG16323, so absence of these genes could be further explored as a possible cause of enhanced pathogenicity on robusta.

In contrast, the arabica population is divergent to both the Coffea strains andtherobusta population in its complement of effector genes. Arabica strains share three unique effectors: Cytoskeletal, the CAZyme OG14180 and OG14179 with a TE in its promoter region. The wiltspecific Cytoskeletal protein was recently described in Fol, V. dahliae and V. albo-atrum and found to be absent from non-wilt inducing Fusarium species [10]. The CAZyme OG14180 encodes for a GH18 chitinase that has an insertion under positive selection relative to the matching copy in the Fol genome, potentially indicating divergent function within the arabica population. In addition, the arabica strains lack 17 effector orthologs found in one or both Coffea strains: gluco, nep1, five small cysteine-rich proteins including a hydrolase and a pectate lyase, and ten CAZymes including five glycoside hydrolases, another glucosyltransferase OG14741, and a CE8 pectinesterase OG7097. Interestingly, two of these hydrolases, OG7097 and OG6324 have apparently inactivated with $20-30 \%$ shorter gene copies which were annotated as two separate genes in both arabica strains: in OG7097 the arabica strains are missing a $500 \mathrm{bp}$ piece of the gene compared with the robusta strains and a stop codon has truncated it into two genes; and in OG6324 arabica563 has two Copia long terminal repeat (LTR) TE insertions and arabica908 has three unknown TE insertions in the middle of this gene, splitting it and presumably removing functionality. Interestingly, the arabica strains have $20 \%$ more copies of these repeats than the robustas, and 35\% more than the Coffea strains. The two glucosyltransferases (predefined gluco and OG14741) are found across the robusta and Coffea strains, F. oxysporum f. sp.'s including Foc, Fol, V. dahliae and V.albo-atrum. The predefined gluco glucosyltransferase is required for full pathogenicity in $V$. dahliae [10], and in F. xylarioides it shares a scaffold with the small cysteine-rich putative effector OG14165, which is also only present in the robusta and Coffea strains (see below). The Nep1 protein induces necrosis and ethylene production in host plants [65] with its family expanded in Fol and $V$. dahliae and purportedly responsible for their broad host ranges [66]. It is noteworthy that no putative CAZyme effectors are shared exclusively between arabica and the Coffea strains, whereas the robusta strains share seven with the Coffea strains.

While these differences confirm separation of the arabica population from the other strains, a few putative effectors displayed contrasting affinities. The four genes highlighted as absent in robusta strains are cases of sharing between Coffea and arabica strains. Of these, six 7 is shared with Coffea659, the only Coffea strain that is also able to infect arabica coffee $[29,50]$, and therefore of possible interest as pathogenicity factors for growth on arabica coffee. Just one gene, OG14797, is shared by robusta and arabica populations but absent in both Coffea strains. Interestingly, this gene gave a significant signal for positive selection and displays considerable amino acid divergence between the two forms (91\% Pairwise Identity). However, both copies share $F$. anthophilum, a member of the American FFC clade [45], as closest relative (with nearly $80 \%$ similarity), while a diverged copy in $F$. verticillioides is closer to F. nygamai ( $84 \%$ similarity), another African FFC clade member [45]. It is possible therefore that this gene diverged rapidly under positive selection for differential function in each population or that these represent separate acquisitions from alternative sources, despite the same closest BLAST match for F. xylarioides. Either way, there is no evidence for substantial recent exchange of effector genes between arabica and the other populations, consistent with genome-wide evidence for their isolation.

We also looked for changes in the number of copies of CAZyme gene families shared by orthologous groups among F. xylarioides strains as a possible cause of changes in the ability to degrade plant cell walls and access carbon from their host. Excluding the groups which matched with non-wilt inducing species, we found differences in vascular wilt-inducing plant cell wall-degrading gene families between robusta and arabica populations, with the Coffea strains, as before, more similar to robusta. Plant cell walls contain pectins, celluloses, hemicelluloses and other polysaccharides which, along with simple sugars such as mannans, wilt fungi can utilise as a carbon source [34, 67]. Comparing robusta and Coffea with arabica, different CAZyme gene families which share functions have expanded across them: the pectinase families CE8, GH78 and GH88 in robusta and Coffea, and PL1 in arabica; the xylanase, xylan being a component of hemicellulose, 
families CE5, GH3, GH43_11, GH43_24 and CBM35 in robusta and Coffea, versus CBM42 and GH43_26 in arabica; and the mannanase families CBM13 and GH134 in robusta and Coffea, and GT22 in arabica. Whilst not specific to pectin, CBM1-containing carbohydrate esterases that bind cellulose and hydrolyse xylans, mannans and pectins [68-70] were only present in robusta strains and Coffea674. While we cannot infer the functional effects of these changes on the infection process, they are suggestive of differences in carbon usage between the two hostspecific populations.

Although the main differences among strains are apparent in gene content, we also found cases of divergent selection acting on the amino acid sequence of some shared genes: for example, OG13861 and OG14828 found in all strains, and OG14398 found in all strains except Coffea659 (Fig. 6). The latter ortholog is the potentially divergent form of six 7 identified as a small cysteine-rich protein and displays amino acid divergence (92\% Pairwise Identity) in a pattern consistent with strain hostspecificity.

\section{Several effector genes have been acquired horizontally by transposable elements}

Previous work has shown the importance of horizontal gene transfer in the spread of new fungal plant pathogens, and we therefore screened our panel of putative effectors for evidence of acquisition by horizontal transfer. We especially considered the hypothesis that effectors associated with wilt-formation might have been acquired from F. oxysporum. We blasted each effector against a panel of Fusarium genomes encapsulating the FFC (the closest relatives of $F$. xylarioides), a wide variety of $F$. oxysporum $\mathrm{f}$. sp.'s (as possible sources of horizontally acquired DNA) as well as distantly related Fusaria, and retrieved hits with $\mathrm{E}>-20$ and length $>90 \%$. We then reconstructed gene trees with alignments of matching genes retrieved from each genome. We expect vertically inherited genes in F. xylarioides to group with FFC lineages, as in the core phylogeny (Fig. 4), whereas horizontally acquired genes to group with $F$. oxysporum.

Across 64 effectors (Fig. 7), seven display no BLAST hit and we consider their origin unknown. All others have positive hits in at least one $F$. oxysporum. Most of these (45) also display at least one hit in an FFC genome, and indeed in 40 of these effectors the F.xylarioides sequences group with FFC sequences, which is consistent with vertical inheritance. Note that nine of these cases had an FFC match only in F. udum, the wilt-forming sister lineage to F. xylarioides (Additional file 2: Table S8, cases annotated with *). Potentially these cases could represent horizontal acquisition from $F$. oxysporum in the common ancestor of F. udum and F. xylarioides, but we focus on putative transfer into the F. xylarioides lineage here and so label these as vertical. The remaining 5 effectors, out of 45 with positive hits in the FFC, group more closely to F. oxysporum lineages with strong support (approximate Likelihood Ratio Test, aLRT support $>0.95$, Additional file 2: Table S8), consistent with horizontal transfer. Among the remaining 14 effectors (of the original 64) with no hits detected in FFC genomes, F. xylarioides copies nest within the variation observed among $F$. oxysporum lineages in 10 cases

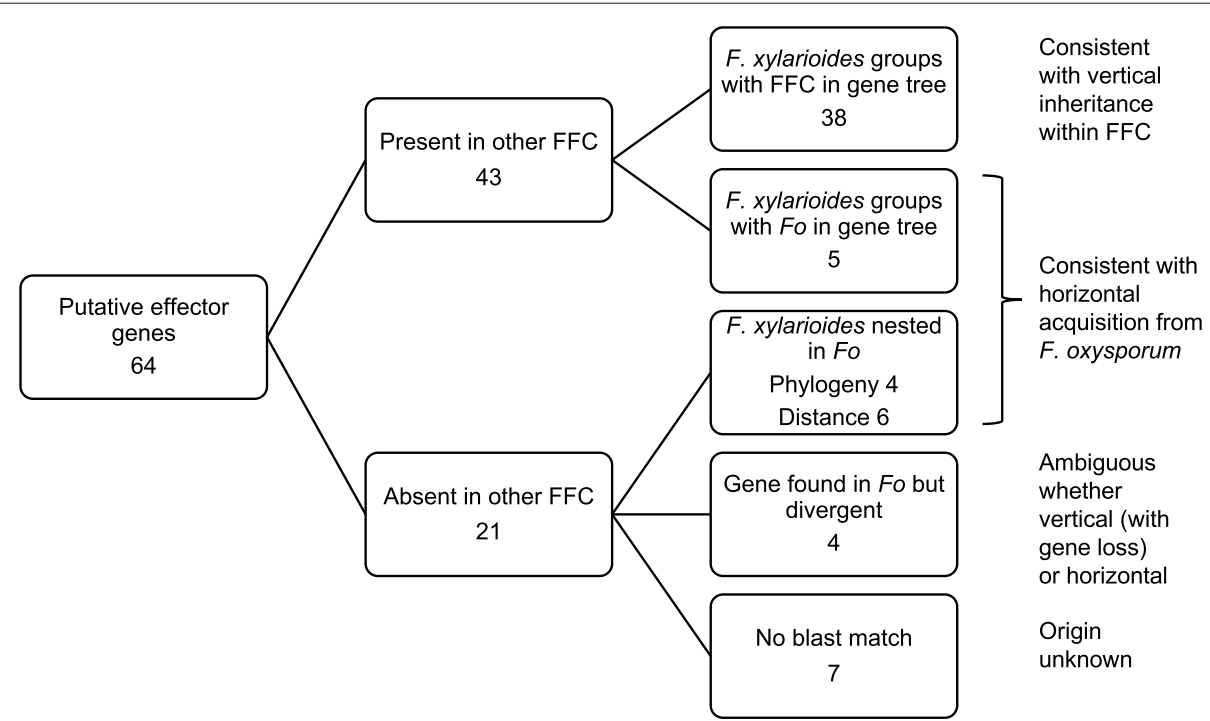

Fig. 7 Horizontal gene transfer between F. xylarioides and F. oxysporum. Decision tree showing the numbers of putative effector genes in $F$. xylarioides (Fxyl) displaying different patterns in their phylogenetic relationships, focusing on possible horizontal acquisition from $F$. oxysporum (Foxy). $\mathrm{FFC}=$ F. fujikuroi complex that F. xylarioides belongs to. Interpretations consistent with each pattern are shown on the right 

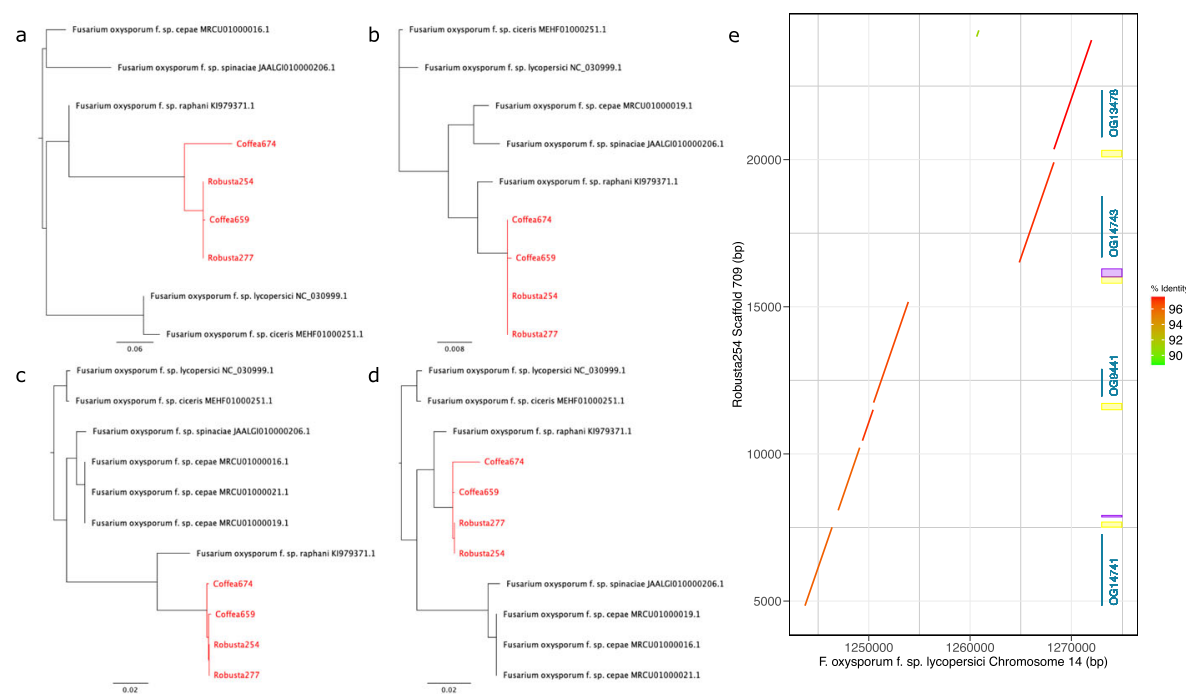

Fig. 8 Four putative effector genes on the robusta254 scaffold and their phylogenetic trees. a Phylogenetic tree for og 14741 , b Phylogenetic tree for og9441, c Phylogenetic tree for og 14743, d Phylogenetic tree for og 13478. For each gene, the FFC is absent, F. xylarioides is nested within F. oxysporum and F. oxysporum f. sp. raphani is the closest match (also shown in Additional file 2: Figure S7). All branch support values $=100 \%$, all trees drawn in Geneious 9.1. e The four effector genes are surrounded by mimps and DNA transposons on a robusta254 scaffold which shares a high (>96\%) nucleotide sequence identity with the mobile and pathogenic Fol chromosome 14. Similar scaffolds with the same four putative effector genes are present in robusta277, Coffea659 and Coffea674. Alignments were made with nucmer (MUMmer3). The blue annotations indicate the effector genes, the yellow annotations indicate mimps and the purple annotations indicate DNA transposons

(based on phylogenetic and distance criteria, see Methods), which is again consistent with horizontal transfer (e.g. Fig. 8a-d). In the final 4 cases, F. xylarioides sequences are highly divergent from all $F$. oxysporum sequences and so a hypothesis of recent horizontal acquisition is not strongly supported. Those genes could have been vertically inherited but secondarily lost in all other FFC lineages, or diverged so much that they returned no match in other genomes, or been acquired horizontally from lineages not included in our sample.

Among the 15 putative effectors with evidence for acquisition by transposition, two are shared by all six $F$. xylarioides strains. Of these, one is the putative divergent form of Six7 (OG14398) that displays evidence of divergent selection between host-specific strains and the other (OG13477) matches a LysM domain. Three effectors are in the arabica strains, with one, another SIX protein (Six10) shared by arabica and the Coffeas, and two effectors unique to the arabica population and both involved in hydrolysis. The remaining ten effectors are shared by the robusta and at least one of the Coffea strains but not arabica. Six of these have recognised functional annotations:Nep1, involved in necrosis; OG16241 and OG15465, hydrolysis of sugars; OG14741,glucosyltransferase; OG14743, squalenehopene-cylase; OG13478, involved in signalling; OG973, transporter protein. Thus HGT from $F$. oxysporum appears to have played a greater role to the emergence of the robusta and Coffea host-specific strains than in the arabica population. Of the formae speciales which consistently match, F. oxysporum f. sp. raphani shares a percent identity $>98 \%$ with four of these HGT effectors only found in the robusta and Coffea strains (Additional file 2: Figure S7).

We further interrogated the 15 possible cases of horizontal transfer from $F$. oxysporum by investigating the flanking regions in our MEGAHIT assemblies. Of particular interest is one scaffold found in the robusta and Coffea genomes, which contains these 4 putative effectors matching $F$ oxysporum f. sp. raphani with evidence for horizontal transfer (OGs 9441, 13478, 14741 and 14743) in each strain (Fig. 8a-d). Additionally, this scaffold is absent from $F$. verticillioides and designated as FXU in section 3.1, for each strain. This $20 \mathrm{~Kb}$ scaffold displays high (>97\%) identity with $F$. oxysporum (Fig. 8e), and further features suggestive of horizontal transfer described in section 3.6. Among the remaining effectors suggestive of HGT, six were found on scaffolds with high identity to $F$. oxysporum which were mostly absent from $F$. verticillioides too, consistent with transfer of a larger region of DNA, whereas five were assembled into a background of low identity, consistent with transfer of a shorter piece of DNA (Additional file 2: Figures S8 and S9).

\section{Evidence that class II TEs play a role in horizontal transfer of putative effectors}

Previous work implicated mimp class II TEs in the HGT of effector genes in F. oxysporum: mimps are strongly 
associated with effector genes [13] and phylogenetic analysis support multiple transfer events between $F$. oxysporum and other FFC species [62]. We therefore investigated the potential role of mimps (Additional file 2: Table S6) in horizontal acquisition of effector genes in F.xylarioides. We find 46 mimps on average per genome, with 59 in the robusta and Coffea strains and 20 in the arabicas, which is at the upper end of estimates in other FFC species [62] $(<20$ in each strain except for $F$. hostae which has 40), despite a potential bias to under-estimate numbers of repetitive TEs in assemblies of short-read data (section 3.1). Most are from the common mimp 1 and 2 families, with $10 \%$ in family 4 in the robusta and Coffea strains and $10 \%$ in the highly divergent and recently described mimp family $m n 14$ in the arabicas (Fig. 9). We also found at least one full, and therefore presumably active, copy of the FOM24 impala transposase ORF (BLAST, $\mathrm{e}=0.00$ ) in each strain. To test whether $F$. oxysporum could be the source of these mimps, we compared nucleotide sequences. Using BLAST, we compared the mimps to the nr database as well as the genomes in Additional file 2: Table S3, and found only hits in F. oxysporum. We found mimps in families 1, 4 and the highly divergent family mn 4 to have $>96 \%$ percent identity ( $>97 \%$ in 1 and $\mathrm{mn} 4$ ) with $F$. oxysporum with high support values (Fig. 9) and the F.xylarioides and $F$. oxysporum mimps as sister clades.

Of the 15 cases of putative horizontal transfer discovered by phylogenetic analysis of effector gene sequences in the previous section, all are found on scaffolds containing mimps and DNA transposons. For example, the $20 \mathrm{~Kb}$ scaffold from Fig. 8e, which is present in the robusta and Coffea genomes, has close affinity to $F$. oxysporum and is enriched and interspersed with class II DNA transposons and mimps. This region matches a chromosomal mini-cluster on Fol's chromosome 14 that contains SIX effectors (being within $1.8 \mathrm{~kb}$ to $33 \mathrm{~kb}$ of SIX genes, Additional file 2: Figure S6, [13]). [13] suggested that effector genes found between interspersed repeat regions on chromosome 14 could coincidentally be transposed with the mimps, which provides a working hypothesis for how F. xylarioides acquired these effectors. In addition, three more putative effectors match to mobile chromosomes that have not been linked with pathogenicity: six 10 and pep 1 match regions of chromosomes 3, 6 and 15, while og14180 matches 3 and 6 .

Beyond these examples, our full set of 64 effector loci tend to be close to TEs: the median distance from a TE for our putative effectors ranges from $2.2 \mathrm{~kb}$ to $3.9 \mathrm{~kb}$, compared to $4.4 \mathrm{~kb}$ to $7.6 \mathrm{~kb}$ on average for random subsets of genes chosen from the whole genome (randomisation test, $\mathrm{p}<0.05$ in robusta277, Coffea674 and arabica563, $\mathrm{p}>0.05$ in the other genomes, Additional file 2: Table S7). These numbers might be underestimates of average distances for effector genes found in lineage specific regions that are rich in repeats and TEs that we were unable to assemble. However, not all of the effectors associated with class II transposons display a signal of HGT in our phylogenetic analysis of effector genes. Another possible explanation for the association is that TEs and effector genes cohabit genome islands with high rates of variability, perhaps with TEs directly contributing to increased variability or modified expression of effector genes. In potential support of this idea, the effector genes from the reference-guided scaffold assemblies tend to be close to LRAR-affected regions targeted heavily by RIP-mutation (section 3.1, median distance from LRAR-affected regions ranges from $6.4 \mathrm{~kb}$ to $22.5 \mathrm{~kb}$, compared to $17.5 \mathrm{~kb}$ to $28 \mathrm{~kb}$ for random subsets of the same number of genes from the whole proteome, $p<0.05$ in robusta254, arabica563, and arabica908, $\mathrm{p}>0.05$ in the other genomes,). RIP-mutation and TE transposition within genomes might therefore provide additional mechanisms for enhancing variability of the effector genes [11], which could be explored by further analyses of population variation.

\section{Discussion}

Using fungal strains collected over a period of 52 years and optimally cryopreserved in a living state, we uncovered the genomic basis of repeated outbreaks of $F$.xylarioides on different commercial coffee species. Our data support the conclusion that the robusta and arabica populations had divergent origins within the $F$. xylarioides clade, with the robusta population deriving from within the earlier outbreaks of more genetically diverse strains on alternative Coffea crops. Furthermore, by cataloguing multiple putative effector and pathogenicity genes, we show how the different host-specific populations diverged in gene content and sequence by vertical processes within lineages, as well as by apparently acquiring 15 putative effector genes by horizontal gene transfer, mostly in the robusta and Coffea strains, from $F$. oxysporum.

The finding that arabica is divergent from the other strains is consistent with earlier work based on crossing experiments and molecular markers, which supports the reclassification of the 1990-2000s host-specific populations as separate species named $F$. abyssiniae (arabica) and F. congoensis (robusta). Our evidence for concordant gene trees across the entire genome, as well as substantial differences in gene content, both overall and specifically for genes thought to be important for the infection process, lends weight to this proposal. Rather than the presumed recent emergence of these strains, the level of diversity we observe is consistent with a divergence far earlier than the emergence within the last 50 years of these populations as major disease agents. Moreover, we found little evidence for transfer of genes from the pre-1970s outbreak into the 1990-2000s epidemic on arabica coffee. We hypothesise 

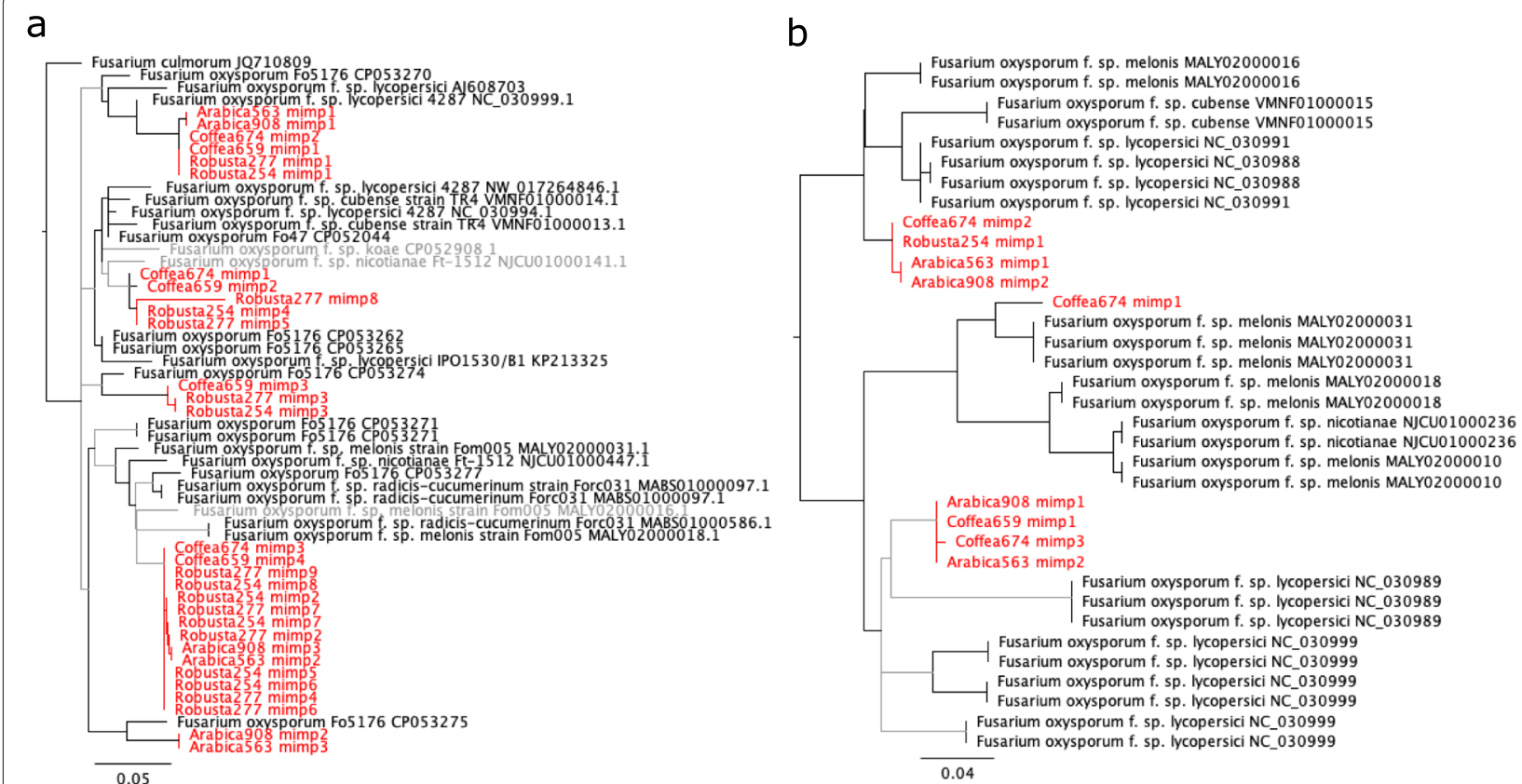

C

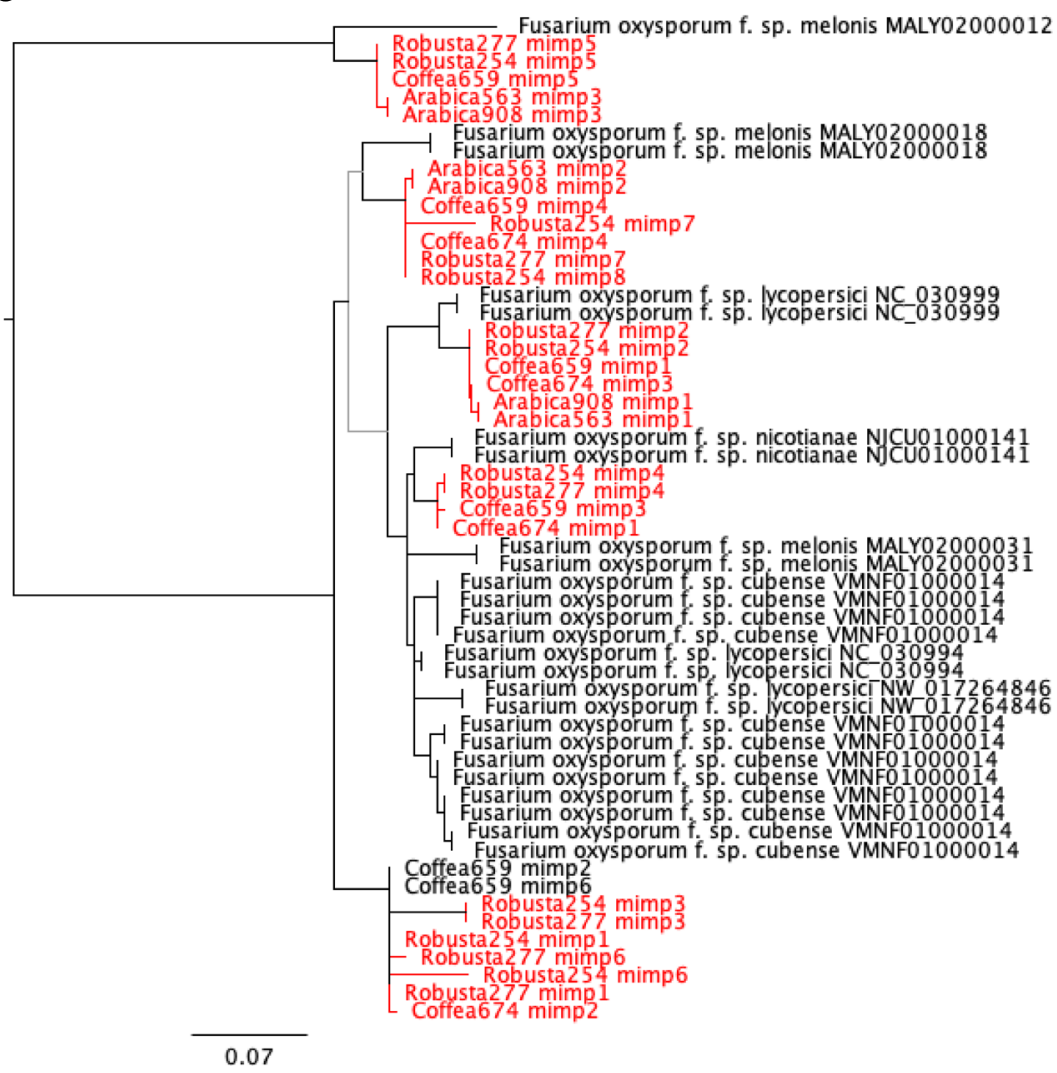

Fig. 9 mimp families found in F.xylarioides. Phylogeny of three mimp families in F. oxysporum, F. xylarioides and F. culmorum (tree rooted with F. culmorum in a). a, mimp family 1. b, mimp family 4. c, mimp family mn4. No other species matches were returned compared to the species in Additional file 2: Table S3 and the nr database (BLAST, 1e-50). Nodes which are coloured in black share a branch support value $>90 \%$, F. xylarioides mimps are annotated in red. Phylogeny was inferred using Chi2 support values. Drawn in Geneious 9.1 
that this represents a separate emergence on commercial arabica coffee from $F$. xylarioides strains associated with wild coffee relatives in Ethiopia or previously less noticeable disease symptoms on arabica coffee, but further sampling, including of wild relatives, would be needed to test this. In contrast, the robusta population evolved with relatively minor modifications from the original outbreak on multiple Coffea species in central and west Africa, with only two putative effector genes gained and a handful lost compared with the Coffea strains sampled here. The high level of similarity between paired strains within each host-specific population, despite sampling from different locations or countries five years apart, supports the emergence of each population from low initial diversity, i.e. each constitutes a single epidemic outbreak replacing earlier variants $[29,71]$.

The observation that 15 effector genes and their flanking regions are class II TE- and mimp-enriched, share a high percent identity with $F$. oxysporum and have emerged nested within F. oxysporum homologs, supports the role of horizontal transfer in the origin of host-specific differences. The mobile pathogenic chromosome of $F$. oxysporum is widely reported to transfer pathogenicity between different strains $[9,13]$. However, to our knowledge, the transfer of pathogenicity has not been reported across different Fusarium species, nor has it been linked with the other mobile chromosomes. F. oxysporum is known to undergo conidial anastomosis [72], so such transposition could have taken place in their shared niche, where both F. xylarioides and F. oxysporum (undescribed f. sp.) have been co-isolated from the roots and wood of CWDinfected coffee in Ethiopia and central Africa, as well as from banana roots where banana and coffee were intercropped in Uganda [29, 41]. F. oxysporum f. sp. cubense (Foc) is widespread on banana in east and central Africa [41]. F. xylarioides is also known to infect tomato fruits [73] and cotton seedlings [74], offering potential alternate hosts. While [75] did not find F. xylarioides in 105 different crop and weed species collected surrounding coffee farms in Uganda, the ability of $F$. xylarioides to infect solanaceous crops and the Kayinja banana cultivar were investigated [71] (no findings published). Therefore, Fol, Foc and F. oxysporum f. sp. vasinfectum (cotton) are of interest, as well as other formae speciales which are the closest match to numerous effectors: $F$. oxysporum f. sp. pisi and F. oxysporum f. sp. raphani. If confirmed, this would suggest avoiding the widespread practice of intercropping species that share closely related pathogens, for example coffee and banana, or weed management for those which share pathogens, for example of solanaceous weeds in crop surroundings. Greater sampling from these taxa and around coffee fields would be needed to further clarify the range of potential donors for horizontally acquired genes.
Contrary to previously described cases in F. oxysporum $[9,13]$, we find no evidence that transfer occurred on a known mobile chromosome, and indeed many of our putative effector genes are spread across our genome scaffolds. It remains possible that an unknown mobile chromosome or chromosomes with some homology to the Fol mobile chromosomes is involved with some of the variation among strains that we observe: we were unable to assemble LS and FXU regions into whole chromosomes, where matches to Fol mobile chromosomes were concentrated. Future long-read sequencing allied to greater sampling of co-occurring taxa would confirm or refute this possibility.

Our results also provide the first insights into the potential genetic basis for pathogenicity in coffee wilt disease. Of 64 putative effector genes we identified, roughly one third were shared by all $F$. xylarioides isolates. These are expected to include genes that contribute to the common pathogenicity traits of these fungi, i.e. those effectors which migrate to and induce vascular wilting first in the main infected stem and latterly in the systemic infection of the coffee tree as visualised as premature ripening of coffee berries [20]. The main differences that we detected between host-specific populations were in gene content and expansion of gene families. For example, while Fusarium is broadly enriched for lytic enzymes involved in carbohydrate metabolism $[55,56]$, and vascular wilt inducers for certain gene families (as also reported by [10]), we found differences between the arabica and robusta populations, particularly in enzymes involved with metabolism of plant cell wall components. Specifically, the host-specific populations had different enzymes although they share similar functions in the hydrolysis of chitins, pectins, xylans, mannose and rhamnose. For example the arabica strains share seven CAZyme copies, whereas the robusta strains share 19 different CAZymes with the Coffea strains that are involved in the breakdown of the same sugars, as well as cellulose (none are found just in the robusta strains). Whilst we cannot precisely infer the phenotypic effects of these changes, expanded cell-wall degrading enzymes imply variation in the capacity or mode of $F$. xylarioides to breakdown plant cell walls. Cell-wall breakdown releases pectins into the xylem vessels, which could unintentionally act as a barrier to further pathogen growth, so pectin-degrading enzymes could break down pectin barriers for the pathogen to spread leading to the external symptoms of wilting as infection progresses [36]. The ability to utilise plant carbon suggests the fungus is able to live within host coffee plants for a long time before the disease state becomes evident [10], something which has been reported from the field for $F$. xylarioides [20]. A key benefit of the availability of living samples is that we can now begin to test the importance of these differences with functional assays. 


\section{Conclusion}

Our results highlight the multigenic nature of how fungi respond to changing crops and host specialisation. The complexity of the process whereby new effectors emerge means that many pathogenicity genes have functional redundancy, whereby disruption of single genes does not affect virulence [76]. Therefore, it is expected that no single gene confers host specificity, but a diverse set of pathogenicity genes is required. In turn, the emergence of newly pathogenic or host-specific strains involves shifts in profiles of multiple genes. This can occur by transfer of whole pathogenicity regions or from the emergence of distinct lineages that diverged over longer periods of time, but later independently emerge as significant crop pathogens, as observed here for the arabica versus robusta populations. Our finding of the transfer of pathogenicity factors between more distantly related taxa raises a particular concern for the currently widespread practice of intercropping plant species which share closely related plant pathogens, which might increase the probability of new virulent pathogens emerging. These findings prove the value of culture collections in providing historic and optimally preserved strains which help us to understand and model the evolution and spread of disease.

\section{Methods}

\section{Strain information}

Six F. xylarioides strains were selected for Illumina MiSeq sequencing (Table 1). All strains were originally collected over a 52 year period from CWD-infected trees and stored in the CABI culture collection (CABI, Egham, Surrey, TW20 9TY). Strains were grown on synthetic low nutrient agar (SNA) at $25^{\circ} \mathrm{C}$, and potato sucrose agar (PSA) with UV irradiation in order to confirm morphological identification following [30]. Following [77], strains were grown in GYM broth and genomic DNA was extracted from $<20 \mathrm{mg}$ of washed mycelium, which was frozen in liquid nitrogen before extraction following the DNeasy Plant Mini Kit (Qiagen, Hilden, Germany) standard protocol.

\section{Genome sequencing and assembly}

For each strain, a single library was prepared with the Illumina TruSeq PCR-free kit and sequenced with the Illumina MiSeq v3 600 cycle kit with 2 x 300 bp paired end sequencing and 350bp insert size at the Department of Biochemistry (University of Cambridge, UK). Low quality bases and adaptors were identified and trimmed (quality score $<20$ ) using TrimGalore 0.6 .0 by Cutadapt (https:// github.com/FelixKrueger/TrimGalore, [78]). Overlapping paired-end reads were merged using FLASH 1.2.11 [79] before being assembled using MEGAHIT 1.2.8 [44] with a final k-mer length of 189 . Assembly metrics were computed using QUAST 5.0.2 [80] (Table 1 and Additional file 2: Table S1). The quality of the genomes in terms of the presence of 303 core eukaryotic genes and 290 core fungal genes was assessed using BUSCO v3.0.2 [81]. All raw sequence data and assembled genomes have been deposited in the relevant International Nucleotide Sequence Database Collaboration (INSDC) databases under the BioProject accession number PRJNA659227 (see Additional file 2: Table S9 for SRA run accessions). For comparison, we selected eleven genomes of related species (Additional file 2: Table S3) selected for being: closely related and wilt-inducers (F. udum, F. oxysporum $f$. sp. lycopersici and $f$. sp. cubense); closely related which occupy the same coffee-plant niche (F. verticillioides , F. solani and F. oxysporum); closely related (F. fujikuroi, F. mangiferae, F. proliferatum); and wiltinducers ( $V$. dahliae and $V$. albo-atrum). Chromosomal and lineage-specific regions in each $F$.xylarioides assembly were identified by whole-genome alignment to the chromosomal level assembly of $F$. verticillioides (GenBank accession GCA_003316975.2, Ma et al. 2010). The Coffea659 assembly (chosen for having the larger genome of the two Coffea strains) was aligned against $F$. verticillioides using RaGOO v1.1 with the '-C' parameter [82], with the remaining $F$. xylarioides strains aligned in-turn against the assembled RaGOO Coffea659. We used BLAST (with $1.00 \mathrm{e}-50)$ to identify scaffold specific groups between the closely related F. xylarioides, F. udum and F. verticillioides: scaffolds which did not match to $F$. verticillioides but are present in each $F$. xylarioides strain and the $F$. udum genome (GCA_002194535.1, Srivastava 2018) were interpreted as Fusarium xylarioides and udum-specific (FXU). Scaffolds which are present only in F.xylarioides were interpreted as F. xylarioides-specific (FXS), while scaffolds which did not match to the historic Coffea659 genome nor the $F$. verticillioides assembly nor $F$. udum were concluded to be lineage-specific (LS). Here, the LS scaffolds relate to the host-specific populations.

\section{Gene prediction and orthologous clustering}

Protein-encoding genes were predicted using the BRAKER v2.1.2 pipeline [83-88], using RNA-seq data from the closely related $F$. verticillioides to guide gene models. RNA-seq reads (SRR10097610) were mapped to each genome using STAR v2.7.3a [89] and the resultant BAM file was input to BRAKER with default settings. BUSCO analysis was performed to assess quality of predicted proteomes, and the GC content of coding sequences was calculated. This was used to calculate GC-equilibrated regions in $20 \mathrm{~kb}$ windows, where GCrich blocks have a GC content within $1 \%$ of that of the coding sequences, as well as AT-rich blocks, where the GC content is $<=0.7$ of the coding sequences content [11]. A Kruskal-Wallis chi-squared test confirmed association between genes and the GC-rich blocks, with a Wilcoxon rank test (Bonferroni adjustment) to confirm 
significance between pairs. Three programs were used to infer functional classification: Interproscan v5.35-74.0 [90]; Superfocus [91] which classifies the proteins by their SEED categories [92]; and NCBI BLAST (https://blast. ncbi.nlm.nih.gov/Blast.cgi) using megaBLAST searches and the $\mathrm{nr}$ database. All proteins lacking significant hits were annotated as hypothetical proteins. OrthoFinder v2.3.8 [93, 94] was used to determine orthologous groups amongst the six $F$. xylarioides strains and eleven related species (Additional file 2: Table S3 and Additional file 1). Orthofinder also reconstructed a species tree from gene trees of the entire set of orthologs reconstructed by FastML (Fig. 4). Concordance of the set of individual gene trees for single ortholog groups was summarised using PhyParts (https://bitbucket.org/blackrim/phyparts/src/ master/), while concordance of the ortholog groups was summarised using venn diagrams drawn with the Venn package in RStudio. Correlations between strains were tested for an excess of sharing using the "SuperExactTest" package in RStudio ([95].

\section{Transposable elements and repeat annotation}

Repeats and transposable elements (TEs) were identified directly from the assembled nucleotides. RepeatModeler v2.0 was run with parameters "-LTRStruct -pa 32" to first construct a custom repeat library for each genome [96]. This library was then used to call TEs and other repeats from the genome scaffolds using RepeatMasker v4.1.0 with the parameters "-pa 32 -lib \$LIB -dir . -alignments gff -no_is" [97]. The distribution of TEs across the genome was represented as the fraction of base pairs within $20 \mathrm{~kb}$ windows assigned to TEs. In the same way as for genes, the association between TEs and AT-rich areas was tested using a Kruskal-Wallis chi-squared and a Wilcoxon rank test (bonferroni adjustment). The separate distribution of Class 1 RNA retrotransposons and Class 2 DNA transposons [98] was also calculated. For comparison, repeats and TEs were also identified from the raw reads using DNAPipeTE [99] for our F. xylarioides strains, as well as Fol (SRA Accession SRR3142258).

The presence of repeat-induced point mutations (RIP) were confirmed using The RIPper bioinformatics tool [49], with default settings applied to identify Large RIP Affected Regions (LRARs), and the RIPCAL [100] RIPindex scan with default threshold settings applied and a scanning subsequence length of $10 \mathrm{~kb}$ for the core chromosome scaffolds and 300bp for the FXU and LS scaffolds to reflect the average sequence length across the different scaffold groups.

\section{Searching for putative effector genes involved in wilt disease}

We adopted a four-pronged approach to search for putative effector genes involved in the host-specificity between the arabica and robusta populations. Only single gene copy orthologous groups were analysed for ease of comparison. We used BLAST to verify inferred patterns of presence and absence based on the orthogroups, and corrected in the twelve cases (annotated with an "a" in Fig. 6) where annotation had missed a full length copy of the gene in certain taxa.

Pre-characterised effectors Putative effector sequences described in closely related Fusarium species were downloaded from Genbank (Additional file 2: Table S3). Using BLAST, the sequences were searched for against the F. xylarioides predicted genes and scaffolds. Proteins were judged to be present if a blast match of $>70 \%$ and $1.00 \mathrm{E}-50$ was obtained and the sequence retrieved from the genome scaffold, checking to include the full protein region if the blast match only returned a partial match.

Small, cysteine-rich putative effectors Many fungal effector proteins are small ( $<400$ amino acids), cysteinerich ( $>4$ cysteine residues) and secreted $[8,52]$. Putative effectors were therefore searched for within each genome based on size, cysteine-richness, secretion signal and putative function. First, annotated genes were sorted according to size and number of cysteine residues using SeqKit [101], to select those with $<400$ amino acids and $>4$ cysteine residues. Next, the presence of a signal peptide and a signal peptide cleavage site on those proteins were predicted using TargetP $1.01[102,103]$ with an RC score cut-off 1-3 to increase specificity. Finally, subcellular localizations for these proteins were predicted using WoLF PSORT (https://wolfpsort.hgc.jp/) to identify secreted extra-cellular proteins. The orthologous gene sets for those genes were identified from the Orthofinder results.

CAZyme effectors CAZymes are carbohydrate-active enzymes thought to be important in the infection pathway. Carbohydrates in plant cell walls provide the main source of carbon for fungal pathogens [54] and consist of cellulose microfibrils embedded in a matrix of hemicelluloses, pectin polysaccharides and glycoproteins [104]. The breakdown of cell wall polymers requires a range of enzymes, including glycoside hydrolases ( $\mathrm{GHs})$, pectate and polysaccharide lyases and carbohydrate esterases (CEs) [34]. CAZymes that target cell walls also contain carbohydrate-binding modules (CBMs) [105], which bind to cell wall polymers and increase the enzymes' catalytic efficiency by improving contact $[54,106]$. CBMs show specificity for particular polymers [107]. Broadly, Fusarium is enriched for CAZymes (Additional file 2: Table S5). Therefore, to identify putative CAZyme-encoding effector genes, and the CBM and their associated carbohydrate active modules differentially expressed across the 
wilt-inducing and non-wilt inducing fungal strains we used the CAZy database (www.cazy.org, [67]) to identify CAZyme-encoding orthologous groups. We looked for those present in only the wilt-inducing strains using BLAST (e-vale 1.00e-50), additionally allowing for those which were present in just one non-wilt inducing strain.

\section{Effector genes with TEs in their promoter regions} In particular, class 2 MITES (Miniature Inverted-repeat Transposable Elements) have been shown to associate with effector proteins [13]. The abundance of class II transposons recognised by RepeatModeler, miniature and full impala transposons, as well as recently described transposons across the genomes was tested using the accessions detailed in Additional file 2: Table S6 and by [61], with a BLAST (score $>70 \%, 1.00 \mathrm{e}-50$, length $>150 \mathrm{bp}$ ) confirming their presence. The presence of an intact impala ORF was confirmed with the intact FOM24 transposase (Genbank accession AF282722.1) using BLAST, 1e-50.

For each set of putative effectors, nucleotide sequences were aligned using MAFFT and maximum likelihood trees reconstructed using PhyML 3.0 [108] with a Generalised Time-Reversible model with invariant sites and gamma distributed variation in substitution rates across 4 rate classes of sites, implemented in Geneious v9.1. We also located each putative effector on the genome scaffolds in each species mapped against the chromosomal level $F$. verticillioides assembly. The site test of positive selection in PAML v4.8 [109] was used to test for positive selection among codons in the DNA sequences in each phylogenetic tree by estimating the ratio between synonymous and nonsynonymous substitutions $(\omega)$. PAML detects positive selection when is significantly greater than 1 for a subset of codons. We compared a null model of "NearlyNeutral" selection that includes a class of codons under purifying selection and a class that evolve neutrally, against an alternative model of "PositiveSelection" that additionally includes a class with $>1$. Log-likehood ratios were calculated and compared with a chi-squared test with one degree of freedom to confirm significance. A Bayes Empirical Bayes (BEB) approach was used to identify specific amino acid sites under positive selection within gene sequences which were confirmed to be under positive selection [110]. We detected horizontal gene transfer by searching for our 64 putative effector genes across the genomes in Additional file 2: Table S3 and $F$. oxysporum forma speciales in Additional file 2: Figure S7. BLAST hits were aligned using MAFFT and maximum likelihood trees reconstructed using approximate Likelihood Ratio Tests $>0.95$. We then followed the decision tree (Fig. 7) to decide if each gene displayed evidence of horizontal gene transfer: is the effector present in other FFC species ( $\mathrm{Y} / \mathrm{N})$; if $\mathrm{Y}$, does F.xylarioides $(F x)$ nest with the FFC gene copies ( $\mathrm{Y} / \mathrm{N}$ ); if $\mathrm{N}$ to either of previous decisions, does Fx nest with $F$. oxysporum (Fo) thus disrupting the Fo phylogeny $(\mathrm{Y} / \mathrm{N})$; branch support values (BSV) for Fx with Fo (n); if N, does Fx nest with Fo by distance i.e. less distance from Fx to Fo than greatest distance from Fo to Fo; pairwise id \% for whole branch with support value for Fx nested with Fo.

\section{Abbreviations}

ISNDC: International Nucleotide Sequence Database Collaboration; f. sp.: formae speciales; BLAST: Basic Local Alignment Search Tool; TE: Transposable Element; CWD: Democratic Republic of Congo; CABI-IMI: CABI International Mycological Institute; SIX: Secreted In Xylem; BUSCO: Benchmarking Universal Single-Copy Orthologs; FFC / GFC: Fusarium fujikuroi complex / Gibberella fujikuroi complex; Fol: Fusarium oxysporum f. sp. Iycopersici; Fv: Fusarium verticillioides; FXU: Fusarium xylarioides and -udum specific; FXS: Fusarium xylarioides-specific; LS: Lineage specific; RIP: Repeat Induced Point-like; LRAR: Large RIP (Repeat Induced Point-like) Affected Regions; Pfam: Protein families; CAZyme: Carbohydrate-active enzyme; CBM: Carbohydrate-binding module; GH: Glycoside hydrolase; MITE: Miniature inverted-repeat transposable element; mimp: Miniature impala; CE: Carbohydrate esterase; LTR: Long terminal repeat; Foc: Fusarium oxysporum f. sp. cubense; PL: Polysaccharide lyase; HGT: Horizontal gene transfer; ORF: Open Reading Frame; Fom: Fusarium oxysporum f. sp. melonis; SNA: Synthetic low nutrient agar; BSV: Branch support values

\section{Supplementary Information}

The online version contains supplementary material available at https://doi.org/10.1186/s12864-021-07700-4

Additional file 1: Orthogroups. Output from Orthofinder v2.3.8 describing the orthologous groups and genes amongst the six F. xylarioides strains and eleven related species.

Additional file 2: Supplemental figures and tables.

\section{Acknowledgements}

We thank G. Senbeta, D. Kilambo, J. Flood, G. Hakiza, J. Kranz and M. Moreau who originally collected the fungal isolates and deposited them in the CABI IMI collection. With thanks to CGR and NERC Metagenomics Workshop and with special thanks to $\mathrm{H}$. Stewart and A. Buddie (CABI) for invaluable lab support and advice, and C. Wilson, P. Spanu, B. Murphy and T. Llewellyn for comments on the manuscript.

\section{Authors' contributions}

LDP, MR, JF, and TGB conceived the study. LDP designed and conducted the experimental work, data analysis, and assembled the genomes. RWN performed the genome annotations and assisted with other analyses. JF and TGB analysed data. JF and MR provided materials. LDP and TGB wrote the paper with contributions from all authors, and all authors approved the final manuscript.

\section{Funding}

This research was supported by the Natural Environment Research Council [grant number NE/L002515/1] (LDP) and NE/S010866/1 (TGB and RWN).

\section{Availability of data and materials}

The genomic sequences of $F$. xylarioides have been deposited at Genbank under the BioProject accession number PRJNA659227. Whole genome data generated in this study has been deposited at the Sequence Read Archive under the following SRA accession numbers: SRR12534416; SRR12534415; SRR12534414; SRR12534413; SRR12534412 and SRR12534411. Further details are in Additional file 2: Table S9. The genome assemblies for F. verticillioides and F. oxysporum f. sp. lycopersici under accession numbers GCA_003316975.2 and GCA_000149955.2 were used in reference-guided scaffolding to align our F. xylarioides scaffolds to their assembled chromosomes. Additional RNA-seq data used in annotation of F. xylarioides and F. udum genomes were obtained from F. vertcillioides under accession number SRR10097610. Proteome data for 
10 Fusarium and Verticillium fungal species used for phylogenetic orthology inference were obtained from Genbank using the following BioProject accessions: F. verticillioides, PRJNA245136; F. fujikuroi, PRJNA322155; F. mangiferae, PRJEB9887; F. proliferatum, PRJNA576857; F. oxysporum f. sp. lycopersici, PRJNA342688; and F. oxysporum f. sp. cubense, PRJNA529756; F. solani, PRJNA16586; F. graminearum, PRJNA243, V. dahliae, PRJNA225532; and V. albo-atrum, PRJNA51263. Recently published genome sequence data for two additional F. xylarioides strains were used for comparison and verification of genome statistics. The data was obtained from Genbank genome database under accession numbers PRJNA530275 and PRJNA508603.

The individual gene sequences used in this study were all obtained from the Genbank database. The sequence data for the 17 known effector genes from fungal plant pathogens used to identify our first class of putative effector genes (section 3.3.1) are described in Additional file 2: Table S4. Additionally, a pathogenic pda1-a allele from sugarbeet (Genbank accession number AY487143.1) was used for comparison to the pdal gene identified in this study. The sequence data for the impala and miniature impala and newly-described class II transposable elements is described in Additional file 2: Table S6, detailing the Genbank accession number, the type of transposon and whether the sequence is partial or complete. Twelve of these transposable elements were not obtained from Genbank, but were obtained from [13], with the reference detailed in Additional file 2: Table S6. The FOM24 transposase, Genbank accession AF282722.1, was used to confirm the presence of an intact impala ORF.

\section{Declarations}

Ethics approval and consent to participate

Not applicable to this study

\section{Consent for publication}

Not applicable to this study

\section{Competing interests}

The authors declare that they have no competing interests.

\section{Author details}

${ }^{1}$ Science and Solutions for a Changing Planet Doctoral Training Partnership, Grantham Institute, Imperial College London, South Kensington, SW7 2AZ London, UK. ${ }^{2}$ Department of Life Sciences, Imperial College London, Silwood Park Campus, Ascot, SL5 7PY Berkshire, UK. ${ }^{3}$ Department of Zoology, University of Oxford, 11a Mansfield Road, OX1 3SZ Oxford, UK. ${ }^{4}$ CABI, Bakeham Lane, Egham, TW20 9TY Surrey, UK.

\section{Received: 21 October 2020 Accepted: 11 May 2021}

\section{Published online: 04 June 2021}

\section{References}

1. Fones HN, Fisher MC, Gurr SJ. Emerging fungal threats to plants and animals challenge agriculture and ecosystem resilience. Microbio Spectr. 2017;5(2):787-809. https://doi.org/10.1128/microbiolspec.FUNK0027-2016.

2. Strange RN, Scott PR. Plant disease: a threat to global food security. Annu Rev Phytopathol. 2005;43:83-116. https://doi.org/10.1146/ annurev.phyto.43.113004.133839.

3. Burdon JJ, Thrall PH. Pathogen evolution across the agro-ecological interface: implications for disease management. Evol Appl. 2008;1(1): 57-65. https://doi.org/10.1111/j.1752-4571.2007.00005.x.

4. Jones JDG, Dangl JL. The plant immune system. Nature. 2006;444: 323-9. https://doi.org/10.1038/nature05286.

5. Möller M, Stukenbrock EH. Evolution and genome architecture in fungal plant pathogens. Nat Rev Microbiol. 2017;15(12):756-71. https://doi.org/ 10.1038/nrmicro.2017.76.

6. Sanchez-Vallet A, Zurich E, Fouche S, Hartmann F, Soyer J, Tellier A, Croll $D$. The genome biology of effector gene evolution in filamentous plant pathogens. Annu Rev Phytopathol. 2018;56:21-40. https://doi.org/ 10.1146/annurev-phyto-080516-035303.

7. Michielse CB, Rep M. Pathogen profile update: Fusarium oxysporum Mol Plant Pathol. 2009;10(3):311-24. https://doi.org/10.1111/j.13643703.2009.00538.x
8. de Jonge R, Bolton MD, Thomma BP. How filamentous pathogens co-opt plants: the ins and outs of fungal effectors. Curr Opin Plant Biol. 2011;14(4):400-6. https://doi.org/10.1016/j.pbi.2011.03.005.

9. Ma LJ, Van Der Does HC, Borkovich KA, Coleman JJ, Daboussi MJ, Di Pietro A, Dufresne M, Freitag M, Grabherr M, Henrissat B, Houterman PM, Kang S, Shim WB, Woloshuk C, Xie X, Xu JR, Antoniw J, Baker SE, Bluhm BH, Breakspear A, Brown DW, Butchko RAE, Chapman S, Coulson R, Coutinho PM, Danchin EGJ, Diener A, Gale LR, Gardiner DM, Goff S, Hammond-Kosack KE, Hilburn K, Hua-Van A, Jonkers W, Kazan K, Kodira CD, Koehrsen M, Kumar L, Lee YH, Li L, Manners JM, Miranda-Saavedra D, Mukherjee M, Park G, Park J, Park SY, Proctor RH, Regev A, Ruiz-Roldan MC, Sain D, Sakthikumar S, Sykes S, Schwartz DC, Turgeon BG, Wapinski I, Yoder O, Young S, Zeng Q, Zhou S, Galagan J, Cuomo CA, Kistler HC, Rep M. Comparative genomics reveals mobile pathogenicity chromosomes in Fusarium. Nature. 2010;464(7287): 367-73. https://doi.org/10.1038/nature08850.

10. Klosterman SJ, Subbarao KV, Kang $S$, Veronese $P$, Gold SE, Thomma BPHJ, Chen Z, Henrissat B, Lee YH, Park J, Garcia-Pedrajas MD, Barbara DJ, Anchieta A, de Jonge R, Santhanam P, Maruthachalam K, Atallah Z, Amyotte SG, Paz Z, Inderbitzin P, Hayes RJ, Heiman DI, Young S, Zeng Q, Engels R, Galagan J, Cuomo CA, Dobinson KF, Ma LJ. Comparative genomics yields insights into niche adaptation of plant vascular wilt pathogens. PLoS Pathog. 2011;7(7):1002137. https://doi.org/10.1371/ journal.ppat.1002137.

11. Rouxel T, Grandaubert J, Hane JK, Hoede C, van de Wouw AP, Couloux A, Dominguez V, Anthouard R, Bally P, Bourras S, Cozijnsen AJ, Ciuffetti LM, Degrave A, Dilmaghani A, Duret L, Fudal I, Goodwin SB, Gout L, Glaser N, Linglin J, J Kema GH, Lapalu N, Lawrence CB, May K, Meyer M, Ollivier D, Poulain J, Schoch CL, Simon A, Spatafora JW, Stachowiak A, Gillian Turgeon B, Tyler BM, Vincent D, Weissenbach J, Amselem L, Quesneville H, Oliver RP, Wincker P, Balesdent N, Howlett $B J$. Effector diversification within compartments of the Leptosphaeria maculans genome affected by Repeat-Induced Point mutations. Nat Communications. 2011;2(1):1-10. https://doi.org/10.1038/ncomms1189.

12. Chuma I, Isobe C, Hotta Y, Ibaragi K, Futamata N, Kusaba M, Yoshida K, Terauchi R, Fujita Y, Nakayashiki H, Valent B, Tosa Y. Multiple translocation of the AVR-Pita effector gene among chromosomes of the rice blast fungus Magnaporthe oryzae and related species. PLoS Pathog. 2011;7(7):1002147. https://doi.org/10.1371/journal.ppat.1002147.

13. Schmidt SM, Houterman PM, Schreiver I, Ma L, Amyotte S, Chellappan B, Boeren S, Takken FLW, Rep M. MITEs in the promoters of effector genes allow prediction of novel virulence genes in Fusarium oxysporum,. BMC Genomics. 2013;14(119):1-21. https://doi.org/10. 1186/1471-2164-14-119.

14. Han Y, Liu X, Benny U, Corby Kistler H, VanEtten HD. Genes determining pathogenicity to pea are clustered on a supernumerary chromosome in the fungal plant pathogen Nectria haematococca. Plant J. 2001;25(3):305-14. https://doi.org/10.1046/j.1365-313X.2001.00969.x.

15. McDonald MC, Taranto AP, Hill E, Schwessinger B, Liu Z, Simpfendorfer S, Milgate A, Solomon PS. Transposon-mediated horizontal transfer of the host-specific virulence protein ToxA between three fungal wheat pathogens. mBio. 2019;10(5):e01515-19. https://doi. org/10.1128/mBio.01515-19.

16. Figueres R. Sur une maladie tres grave du cafeier en Oubangui. Technical report. Rapport. Ministere des Colonies, Paris, France. 1940.

17. Saccas A. Recherches expérimentales sur la trachéomycose des caféiers en Oubangui-Chari. Agronomie Tropicale. 1956;11:7-58.

18. Pebesma E. Simple features for R: Standardized support for spatial vector data. R Journal. 2018;10(1):439-46. https://doi.org/10.32614/RJ-2018009.

19. Wickham H. ggplot2: Elegant Graphics for Data Analysis. New York: Springer-Verlag; 2016. https://ggplot2.tidyverse.org.

20. Flood J. Coffee Wilt Disease. Wallingford, UK: CAB International: CABI; 2009.

21. Kalonji-Mbuyi A, Tshilenge-Djim P, Saiba N. Coffee wilt disease in Democratic Republic of Congo. In: Flood J, editor. Coffee Wilt Disease; 2009. http://the-eye.eu/public/Books/Medical/texts/CoffeeWiltDiseaseJ.Flood\%28CABI\%2C2009\%29WW.pdf\#page=20.

22. Stewart RB. Some plant diseases occurring in Kaffa province, Ethiopia. Imp Ethiop Coll Agric Mech Arts. 1957;3:15-6.

23. Lejeune JBH. Rapport au Gouvernement imperial d'Ethiopie sur la production. Rome: FAO Rapport PEAT 797; 1958. 
24. Kranz J, Mogk M. Phytopathologische Zeitschrift Journal of phytopathology,. Phytopathol Z. 1973;78(4):365-6.

25. Van Der Graaff NA, Pieters R. Resistance levels in Coffea arabica to Gibberella xylarioides and distribution pattern of the disease. Neth J Plant Pathol. 1978;84:117-20.

26. Olal S, Olango N, Kiggundu A, Ochwo S, Adriko E, Nanteza A, Matovu E, Gw L, Kagezi G, Hakiza GJ, Wagoire W, Rutherford M, Opiyo S. Using Translation Elongation Factor Gene to specifically detect and diagnose Fusarium xylaroides, a Causative Agent of Coffee Wilt Disease in Ethiopia, east and central Africa. J Plant Pathol Microbiol. 2018;9(440):2. https://doi.org/10.4172/2157-7471.1000440.

27. Mulatu A, Shanko D. Incidence and Prevalence of Coffee wilt Disease ( Gibberella xylarioides ) and Its Impact on the Rural Livelihoods in Western Guji Zone, Southern Ethiopia. Am J Biosci. 2019;7(1):7-15. https://doi.org/10.11648/j.ajbio.20190701.12.

28. Lepoint PCE, Munaut FTJ, Maraite HMM. Gibberella xylarioides Sensu Lato from Coffea canephora: a New Mating Population in the Gibberella fujikuroi Species Complex. Appl Environ Microbiol. 2005;71(12):8466-71. https://doi.org/10.1128/AEM.71.12.8466-8471.2005.

29. Flood J. Epidemiology and variability of Gibberella xylarioides, the coffee wilt pathogen. R8188 (ZA0505). Final Technical Report. Technical report. International, CAB, Wallingford, UK. 2005. http://agris.fao.org/agrissearch/search.do? recordID=GB2012104102.

30. Buddie AG, Crozier J, Rutherford MA, Flood J, Bridge PD. Population development within the coffee wilt pathogen Gibberella xylarioides reflects host-related divergence. Eur J Plant Pathol. 2015;142(2):291-304. https://doi.org/10.1007/s10658-015-0613-z.

31. Olal S, Bitalo DN, Olango ND, Mulindwa J, Ochwo S, Opiyo SO, Arinaitwe G, Ogwok E. De Novo Genome Sequence of a Fusarium xylarioides Race Pathogenic to Robusta Coffee (Coffea canephora) in Uganda. Microbiol Res Announc. 2019;8(31):00520-19. https://doi.org/ 10.1128/MRA.00520-19.

32. Wingfield BD, Fourie A, Simpson MC, Bushula-Njah VS, Aylward J, Barnes I, Coetzee MPA, Dreyer LL, Duong TA, Geiser DM, Roets F, Steenkamp ET, van der Nest MA, van Heerden CJ, Wingfield MJ. IMA Genome-F 11. IMA Fungus. 2019;10(1):13. https://doi.org/10.1186/ s43008-019-0013-7.

33. Tjamos E, Beckman C. Vascular Wilt Diseases of Plants: Basic Studies and Control (NATO ASI Series H: Cell Biology). Berlin, Germany: Springer; 1989.

34. ME Mace AB, Beckman C. Fungal Wilt Diseases of Plants. New York: Academic Press; 1981.

35. Sharma M, Sengupta A, Ghosh R, Agarwal G, Tarafdar A, Nagavardhini A, Pande S, Varshney RK. Genome wide transcriptome profiling of Fusarium oxysporum $\mathrm{fsp}$. ciceris conidial germination reveals new insights into infection-related genes. Sci Rep. 2016;6(37353):1-11. https://doi.org/10.1038/srep37353.

36. Clérivet A, Déon V, Alami I, Lopez F, Trees JG. Tyloses and gels associated with cellulose accumulation in vessels are responses of plane tree seedlings (Platanus $x$ acerifolia) to the vascular fungus Ceratocystis fimbriata f. Springer. 2000;15(1):25-31. https://doi.org/10.1007/ s004680000063.

37. Abo K, Klein KK, Edel-Hermann V, Gautheron N, Traore D, Steinberg C. High genetic diversity among strains of Fusarium oxysporum f. sp. vasinfectum from cotton in Ivory Coast. Phytopathology. 2005;95(12): 1391-6. https://doi.org/10.1094/PHYTO-95-1391.

38. Ellis ML, Cruz Jimenez DR, Leandro LF, Munkvold GP. Genotypic and Phenotypic Characterization of Fungi in the Fusarium oxysporum Species Complex from Soybean Roots. Phytopathology. 2014;104: 1329-39. http://dx.doi.org/10.1094/PHYTO-02-14-0043-R.

39. Ellis ML, Lanubile A, Garcia C, Munkvold GP. Association of Putative Fungal Effectors in Fusarium oxysporum with Wilt Symptoms in Soybean. Phytopathology. 2016;106:762-73. https://doi.org/10.1094/ PHYTO-11-15-0293-R.

40. O'Donnell K, Kistler HC, Cigelnik E, Ploetz RC. Multiple evolutionary origins of the fungus causing Panama disease of banana: Concordant evidence from nuclear and mitochondrial gene genealogies. Proc Natl Acad Sci. 1998;95(5):2044-9. https://doi.org/10.1073/pnas.95.5.2044.

41. Serani S, Taligoola HK, Hakiza GJ. An investigation into Fusarium spp. associated with coffee and banana plants as potential pathogens of robusta coffee. Afr J Ecol. 2007;45(Suppl. 1):91-5. https://doi.org/10. 1111/j.1365-2028.2007.00744.x.
42. Adugna G. Diversity in Pathogenicity and Genetics of Gibberella xylarioides (Fusarium xylarioides) Populations and Resistance of Coffea spp. in Ethiopia. PhD thesis: Rheinischen Friedrich-Wilhelms-Universitat zu Bonn; 2004, p. 85. https://cuvillier.de/de/shop/publications/2907.

43. Lepoint PCE. Speciation within the African Coffee Wilt Pathogen. PhD thesis. Universite Catholique de Louvain. 2006.

44. Li D, Liu C, Luo R, Sadakane K, Lam T. MEGAHIT: an ultra-fast single-node solution for large and complex metagenomics assembly via succinct de Bruijn graph. Bioinformatics. 2015;31(10):1674-6.

45. Kvas M, Marasas W, Wingfield B, Wingfield M, Steenkamp E. Diversity and evolution of Fusarium species in the Gibberella fujikuroi complex. Fungal Divers. 2009;34:1-21

46. Srivastava AK, Kashyap PL, Chakdar H, Kumar M, Srivastava AK, Yadav J, Jamali H, Srivastava R, Sharma A, Tiwari P, Singh A, Saxena AK. First de novo draft genome sequence of the pathogenic fungus Fusarium udum F02845, associated with pigeonpea (Cajanus cajan L. Millspaugh) wilt. Microbiol Res Announc. 2018;7(3). https://doi.org/10.1128/mra.01001-18.

47. Rutherford MA. Current knowledge of coffee wilt disease, a major constraint to coffee production in Africa. Phytopathology. 2006;96(6): 663-6. https://doi.org/10.1094/PHYTO-96-0663.

48. Geiser DM, Lewis Ivey ML, Hakiza G, Juba JH, Miller SA. Gibberella xylarioides (anamorph: Fusarium xylarioides), a causative agent of coffee wilt disease in Africa, is a previously unrecognized member of the G. fujikuroi species complex. Mycologia. 2005;97(1):191-201. https://doi. org/10.1080/15572536.2006.11832853.

49. Van Wyk S, Harrison CH, Wingfield BD, De Vos L, Van Der Merwe NA, Steenkamp ET. The RIPper, a web-based tool for genome-wide quantification of Repeat-Induced Point (RIP) mutations. PeerJ. 2019;2019(8):7447. https://doi.org/10.7717/peerj.7447.

50. Girma A, Million A, Hindorf H, Arega Z. Coffee wilt disease in Ethiopia. In: Flood J, editor. Coffee Wilt Disease. Wallingford, UK: CAB International; 2009. p. 50-68. Chap. Four. https://books.google.co.uk/ books?h|=en\&|r=\&id=|7hWV_o7ExAC\&oi=fnd\&pg=PA50\&dq=girma,+ coffee+wilt+disease+in+ethiopia\&ots $=152$ CnW8BSc\&sig $=$ r04TNawRHMW1JZafpBTrl3sZfG4.

51. Jones DA, Bertazzoni S, Turo CJ, Syme RA, Hane JK. Bioinformatic prediction of plant-pathogenicity effector proteins of fungi. Curr Opin Microbiol. 2018;46:43-9. https://doi.org/10.1016/j.mib.2018.01.017.

52. Van Esse PH, Van't Klooster JW, Bolton MD, Yadeta KA, Van Baarlen P, Boeren S, Vervoort J, De Wit PJGM, Thomma BPHJ. The Cladosporium fulvum virulence protein Avr2 inhibits host proteases required for basal defense. Am Soc Plant Biol. 2008;20:1948-63. https://doi.org/10.1105/ tpc.108.059394.

53. De Jonge R, Van Esse HP, Kombrink A, Shinya T, Desaki Y, Bours R, Van Der Krol S, Shibuya N, Joosten MHAJ, Thomma BPHJ. Conserved fungal LysM effector Ecp6 prevents chitin-triggered immunity in plants. Science. 2010;329(5994):953-5. https://doi.org/10.1126/science.1190859.

54. Hervé C, Rogowski A, Blake AW, Marcus SE, Gilbert HJ, Knoxa JP. Carbohydrate-binding modules promote the enzymatic deconstruction of intact plant cell walls by targeting and proximity effects. Proc Natl Acad Sci U S A. 2010;107(34):15293-8. https://doi.org/10.1073/pnas. 1005732107

55. Reis H, Pfiff S, Hahn M. Molecular and functional characterization of a secreted lipase from Botrytis cinerea. Mol Plant Pathol. 2005;6(3):257-67. https://doi.org/10.1111/j.1364-3703.2005.00280.x.

56. Soanes DM, Alam I, Cornell M, Wong HM, Hedeler C, Paton NW, Rattray M, Hubbard SJ, Oliver SG, Talbot NJ. Comparative genome analysis of filamentous fungi reveals gene family expansions associated with fungal pathogenesis. PLoS ONE. 2008;3(6):2300. https://doi.org/10. 1371/journal.pone.0002300.

57. Howell C, Bell A, Stipanovic R. Effect of aging on flavonoid content and resistance of cotton leaves to Verticillium wilt. Physiol Plant Pathol. 1976;8(2):181-8.

58. Beckman C. Production of Pectinase, Cellulases, and growth-promoting substance by Ceratostomella Ulmi. Phytopathology. 1956;46:605-9.

59. Langcake P, Drysdale R. The role of pectic enzyme production in the resistance of tomato to Fusarium oxysporum f. Iycopersici. Physiol Plant. 1975;6(3):247-58.

60. Talboys P, Society LB. Pectic enzymes produced by Verticillium species. Trans Br Mycol Soc. 1970;55(3):367-81.

61. Bergemann M, Lespinet O, M'Barek SB, Daboussi MJ, Dufresne M. Genome-wide analysis of the Fusarium oxysporum mimp family of MITEs 
and mobilization of both native and de novo created mimps. J Mol Evol. 2008;67(6):631-42. https://doi.org/10.1007/s00239-008-9164-7.

62. van Dam P, Rep M. The distribution of miniature impala elements and SIX genes in the Fusarium genus is suggestive of horizontal gene transfer. J Mol Evol. 2017;85(1-2):14-25. https://doi.org/10.1007/s00239017-9801-0.

63. Covey PA, Kuwitzky B, Hanson M, Webb KM. Multilocus Analysis Using Putative Fungal Effectors to Describe a Population of Fusarium oxysporum from Sugar Beet. Phytopathology. 2014;104(8):886-96. https://doi.org/10.1094/PHYTO-09-13-0248-R.

64. Coleman JJ, Wasmann CC, Usami T, White GJ, Temporini ED, McCluskey K, Van Etten HD. Characterization of the gene encoding pisatin demethylase (FoPDA1) in Fusarium oxysporum. Mol Plant Microbe Interact. 2011;24(12):1482-91. https://doi.org/10.1094/MPMI05-11-0119.

65. Pemberton CL, Salmond GPC. The Nep1-like proteins - A growing family of microbial elicitors of plant necrosis. Mol Plant Pathol. 2004;5(4):353-9. https://doi.org/10.1111/j.1364-3703.2004.00235.x.

66. Yadeta KA, J Thomma BPH. The xylem as battleground for plant hosts and vascular wilt pathogens. Front Plant Sci. 2013;4:1-12. https://doi. org/10.3389/fpls.2013.00097.

67. Lombard V, Golaconda Ramulu H, Drula E, Coutinho P, Henrissat B. The carbohydrate-active enzymes database (CAZy) in 2013. Nucleic Acids Res. 2013:42(D1):490-5.

68. Kellett LE, Poole DM, Ferreira LMA, Durrant AJ, Hazlewoodt GP, Gilbert $\mathrm{HJ}$. Xylanase $B$ and an arabinofuranosidase from Pseudomonas fluorescens subsp. cellulosa contain identical cellulose-binding domains and are encoded by adjacent genes. Biochem J. 1990;272:369-76.

69. Hogg D, Pell G, Dupree P, Goubet F, Martin-Oru; E SM, Armand S, Gillbert HJ. The modular architecture of Cellvibrio japonicus mannanases in glycoside hydrolase families 5 and 26 points to differences in their role in mannan degradation. Biochem J. 2003;371(3):1027-43.

70. McKie VA, Vinoken JP, Voragen AGJ, Van Den Broek LAM, Stimson E, Gilbert HJ. A new family of rhamnogalacturonan lyases contains an enzyme that binds to cellulose. Biochem J. 2001;355(1):167-77. https:// doi.org/10.1042/bj3550167.

71. Phiri N, Baker P. Coffee Wilt in Africa: Final Technical Report of the Regional Coffee Wilt Programme (2000-2007.Technical report. CABI, Wallingford, UK: CAB International. 2009. http://agris.fao.org/agrissearch/search.do?recordID=GB2012104103.

72. Kurian SM, Di Pietro A, Read ND. Live-cell imaging of conidial anastomosis tube fusion during colony initiation in Fusarium oxysporum. PLoS ONE. 2018;13(5):0195634. https://doi.org/10.1371/ journal.pone.0195634.

73. Onesirosan PT, Fatunla T. Fungal Fruit Rots of Tomatoes in Southern Nigeria. J Hortic Sci. 1976;51(4):473-9. https://doi.org/10.1080/00221589. 1976.11514715

74. Pizzinatto M, Menten J. Pathogenicity of eight Fusarium species isolated from seeds to cotton seedlings. Summa Phytopathol. 1991;17(2):124-34.

75. Kangire A, Kytere D, Hakiza G, Warren H, Erbaugh M, Kabole C. Determination of alternate hosts for $F x$, the causal agent of Coffee Wilt Disease (CWD) in Uganda. Technical report. CORI, Uganda. 2002.

76. Reignault P, Valette-Collet O, Boccara M. The importance of fungal pectinolytic enzymes in plant invasion, host adaptability and symptom type. Eur J Plant Pathol. 2008;120(1):1-11. https://doi.org/10.1007/ s10658-007-9184-y.

77. Cubero OF, Crespo A, Fatehi J, Bridge PD. Plant Systematics and Evolution DNA extraction and PCR amplification method suitable for fresh, herbarium-stored, lichenized, and other fungi. Plant Syst Evol. 1999;216:243-9

78. Martin M. Cutadapt removes adapter sequences from high-throughput sequencing reads. EMBnet J. 2011;17(1):10-2. https://doi.org/10.14806/ ej.17.1.200.

79. Magoč T, Salzberg SL. FLASH: fast length adjustment of short reads to improve genome assemblies. Bioinformatics. 2011;27(21):2957-63. https:/academic.oup.com/bioinformatics/article-abstract/27/21/2957/ 217265.

80. Mikheenko A, Prjibelski A, Saveliev V, Antipov D, Gurevich A. Versatile genome assembly evaluation with QUAST-LG. Bioinformatics. 2018;34: $142-50$.

81. Simão FA, Waterhouse RM, loannidis P, Kriventseva EV, Zdobnov EM. BUSCO: user guide. Bioinformatics. 2015;31(19):3210-2. https://doi.org/ 10.1093/bioinformatics/btv351.
82. Alonge M, Soyk S, Ramakrishnan S, Wang X, Goodwin S, Sedlazeck FJ, Lippman ZB, Schatz MC. RaGOO: Fast and accurate reference-guided scaffolding of draft genomes. Genome Biol. 2019;20(1):224. https://doi. org/10.1186/s13059-019-1829-6.

83. Stanke M, Schöffmann O, Morgenstern B, Waack S. Gene prediction in eukaryotes with a generalized hidden Markov model that uses hints from external sources. BMC Bioinformatics. 2006;7:1-11. https://doi.org/ 10.1186/1471-2105-7-62.

84. Stanke M, Diekhans M, Baertsch R, Haussler D. Using native and syntenically mapped CDNA alignments to improve de novo gene finding. Bioinformatics. 2008;24(5):637-44. https://doi.org/10.1093/ bioinformatics/btn013.

85. Li H, Handsaker B, Wysoker A, Fennell T, Ruan J, Homer N, Marth G, Abecasis G, Durbin R. The sequence alignment/map format and SAMtools. Bioinformatics. 2009;25(16):2078-9.

86. Barnett D, Garrison E, Quinlan A, Stromberg M, Marth G. BamTools: a $\mathrm{C}++\mathrm{API}$ and toolkit for analyzing and managing BAM files. Bioinformatics. 2011;27(12):1691-2.

87. Hoff K, Lange S, Lomsadze A, Borodovsky M, Stanke M. BRAKER1: unsupervised RNA-Seq-based genome annotation with GeneMark-ET and AUGUSTUS. Bioinformatics. 2016;32(5):767-9.

88. Hoff KJ, Lomsadze A, Borodovsky M, Stanke M. Whole-genome annotation with BRAKER. Methods Mol Biol. 2019;1962:65-95. https:// doi.org/10.1007/978-1-4939-9173-0_5.

89. Dobin A, Davis C, Schlesinger F, Drenkow J, Zaleski C, Jha S, Batut P, Chaisson M, Gingeras T. STAR: ultrafast universal RNA-seq aligner. Bioinformatics. 2013;29(1):15-21.

90. Jones P, Binns D, Chang H, Fraser M, Li W. InterProScan 5: genome-scale protein function classification. Bioinformatics. 2014;30(9):1236-40.

91. Silva G, Green K, Dutilh B, Edwards R. SUPER-FOCUS: a tool for agile functional analysis of shotgun metagenomic data. Bioinformatics. 2016;32(3):354-61. https://doi.org/10.1093/bioinformatics/btv584.

92. Aziz RK, Devoid S, DiszT, Edwards RA, Henry CS, Olsen GJ, Olson R, Overbeek R, Parrello B, Pusch GD, Stevens RL, Vonstein V, Xia F. SEED Servers: High-Performance Access to the SEED Genomes, Annotations, and Metabolic Models. PLoS ONE. 2012;7(10):48053. https://doi.org/10. 1371/journal.pone.0048053.

93. Emms D, Kelly S. STRIDE: species tree root inference from gene duplication events. Mol Biol Evol. 2017;34(12):3267-78. https://doi.org/ 10.1093/molbev/msx259.

94. Emms DM, Kelly S. OrthoFinder: Phylogenetic orthology inference for comparative genomics. Genome Biol. 2019;20(238):1-14. https://doi. org/10.1186/s13059-019-1832-y.

95. Wang $M$, Zhao $Y$, Zhang B. Efficient test and visualization of multi-set intersections. Sci Rep. 2015;5(16923):1-12. https://doi.org/10.1038/ srep16923.

96. Flynn JM, Hubley R, Goubert C, Rosen J, Clark AG, Feschotte C, Smit $A F$, Org A. RepeatModeler2: automated genomic discovery of transposable element families. Proc Natl Acad Sci. 2020;117(17):9451-7. https://doi.org/10.1101/856591.

97. Smit AFA, Hubley R, Green P. RepeatMasker. Inst Syst Biol. 2021. http:// repeatmasker.org. Accessed 14 May 2020.

98. Daboussi M-J, Capy P. Transposable Elements in Filamentous Fungi. Annu Rev Microbiol. 2003;57(1):275-99. https://doi.org/10.1146/ annurev.micro.57.030502.091029.

99. Goubert C, Modolo L, Vieira C, ValienteMoro C, Mavingui P, Boulesteix M. De Novo Assembly and Annotation of the Asian Tiger Mosquito (Aedes albopictus) Repeatome with dnaPipeTE from Raw Genomic Reads and Comparative Analysis with the Yellow Fever Mosquito (Aedes aegypti). Genome Biol Evol. 2015;7(4):1 192-205. https://doi.org/10. 1093/gbe/evv050. https://academic.oup.com/gbe/article-pdf/7/4/ 1192/17925458/evv050.pdf.

100. Hane JK, Oliver RP. RIPCAL: A tool for alignment-based analysis of repeat-induced point mutations in fungal genomic sequences. BMC Bioinformatics. 2008;9(478):1-12. https://doi.org/10.1186/1471-2105-9478.

101. Shen W, Le S, Li Y, Hu F. SegKit: A cross-platform and ultrafast toolkit for FASTA/Q file manipulation. PLOS ONE. 2016;11(10):0163962. https://doi. org/10.1371/journal.pone.0163962.

102. Emanuelsson $\mathrm{O}$, Nielsen $H$, Brunak S, Von Heijne G. Predicting subcellular localization of proteins based on their $\mathrm{N}$-terminal amino acid sequence. J Mol Biol. 2000;300(4):1005-16. https://doi.org/10.1006/jmbi. 2000.3903. 
103. Nielsen H, Engelbrecht J, Brunak S, Von Heijne G. Identification of prokaryotic and eukaryotic signal peptides and prediction of their cleavage sites. Protein Eng. 1997;10(1):1-6. https://doi.org/10.1093/ protein/10.1.1.

104. Carpita NC, Gibeaut DM. Structural models of primary cell walls in flowering plants: Consistency of molecular structure with the physical properties of the walls during growth. Plant J. 1993;3(1):1-30. https:// doi.org/10.1111/j.1365-313X.1993.tb00007.x.

105. Boraston AB, Bolam DN, Gilbert HJ, Davies GJ. Carbohydrate-binding modules: Fine-tuning polysaccharide recognition. Biochem J. 2004;382(3):769-81. https://doi.org/10.1042/BJ20040892.

106. Carrard G, Koivula A, Söderlund H, Beguin P. Cellulose-binding domains promote hydrolysis of different sites on crystalline cellulose. Proc Natl Acad Sci. 2000;97(19):10342-7.

107. McCartney L, Blake A, Flint J, Bolam D, Boraston A, Gilbert H, Knox J, 2006 U. Differential recognition of plant cell walls by microbial xylan-specific carbohydrate-binding modules. Proc Natl Acad Sci. 2006;103(12):4765-70

108. Guindon S, Delsuc F, Dufayard JF, Gascuel O. Estimating maximum likelihood phylogenies with PhyML. Methods Mol Biol. 2009;537:113-37. https://doi.org/10.1007/978-1-59745-251-9_6.

109. Yang Z. PAML 4: phylogenetic analysis by maximum likelihood. Mol Biol Evol. 2007;24(8):1586-91.

110. Yang Z, Wong WSW, Nielsen R. Bayes empirical Bayes inference of amino acid sites under positive selection,. Mol Biol Evol. 2005;22(4): 1107-18. https://doi.org/10.1093/molbev/msi097.

\section{Publisher's Note}

Springer Nature remains neutral with regard to jurisdictional claims in published maps and institutional affiliations.

\section{Ready to submit your research? Choose BMC and benefit from:}

- fast, convenient online submission

- thorough peer review by experienced researchers in your field

- rapid publication on acceptance

- support for research data, including large and complex data types

- gold Open Access which fosters wider collaboration and increased citations

- maximum visibility for your research: over 100M website views per year

At $B M C$, research is always in progress.

Learn more biomedcentral.com/submissions 